\title{
PANORAMA DE LA RESPONSABILIDAD CIVIL DE LOS PROFESIONALES SANITARIOS POR WRONGFUL BIRTHY WRONGFUL LIFE
}

\author{
Andrea Macía Morillo*
}

RESUMEN

A lo largo del siglo xx se ha producido un incremento de las demandas de responsabilidad civil, así como, especialmente, de responsabilidad civil médica. Este incremento ha llevado a la pretensión de reparación de nuevos tipos de daños, entre ellos, los daños asociados al nacimiento o a la vida. En este trabajo se analizan dos de estas nuevas pretensiones de reparación de daños (las acciones de wrongful birth y wrongful life), en las que se plantea la posibilidad de reclamar responsabilidad a un profesional sanitario en el supuesto de nacimiento de un niño afectado por enfermedades o defectos físicos o síquicos de los que no fueron informados los progenitores previamente a la concepción o durante el embarazo. El análisis se aborda desde la perspectiva de la concurrencia de los elementos de la responsabilidad en ambos tipos de demandas. Dos de ellos, el daño y la relación de causalidad, aparecen como los principales obstáculos a la pretensión de indemnización ejercitada por los progenitores y por el niño en estos casos.

Palabras clave: Wrongful birth, wrongful life, responsabilidad médica, diagnóstico prenatal.

\section{AbSTRact}

During the 20th. Century, tort law claims have increased its number and importance, specially in the field of medical malpractice. Such an increase has led to new kind of damages, such as the damages related with birth and life in general. This paper studies two of this new birth related claims (namely, wrongful birth and wrongful life claims). The question is if a doctor

* Doctora en Derecho Universidad Autónoma de Madrid. Profesora ayudante Facultad de Derecho de la Universidad Autónoma de Madrid. Correo electrónico: andrea.macia@ uam.es. Artículo recibido el 11 de marzo de 2009 y aceptado el 6 de abril de 2009. 
can be sued for liability when a child is born handicapped or with mental or body diseases and no information was passed on to the parents, during the pregnancy or prior to the conception, regarding the child's serious diseases. To answer that question, the paper analyzes the elements of civil liability in both kinds of claims, coming to the conclusion that damage and causation are the main problems of the parents and the child's claims.

Keywords: Wrongful birth, wrongful life, medical liability, prenatal diagnosis.

\section{INTRODUCCIÓN}

Desde mediados del siglo Xx se ha planteado en diversos países una serie de demandas de responsabilidad civil relacionadas con el comienzo de la vida, conocidas generalmente bajo la terminología anglosajona de wrongful birth y wrongful life. Con esta expresión se designan dos tipos distintos de acciones de responsabilidad civil que se pueden plantear contra los profesionales médicos que, con ocasión de una prestación sanitaria de diagnóstico preconceptivo o prenatal, omiten comunicar a los futuros progenitores cierta información sobre los riesgos que amenazan a la descendencia futura, o sobre las enfermedades o defectos de la ya concebida, o emiten un diagnóstico erróneo sobre el estado enfermo o discapacitado físico o síquico de un embrión o feto, o sobre los riesgos que amenazan a los futuros concebidos. Concretamente, la información que reciben los progenitores es que no existen los riesgos, enfermedades o defectos graves que se encuentran realmente presentes en el embrión o feto y que podían haber sido diagnosticados conforme a la lex artis (esto es, lo que se llama un "falso negativo" en el diagnóstico). Sobre este presupuesto, y partiendo de la hipótesis de que aquello de lo que no se informa a los progenitores carecía de cura, de acuerdo con el estado actual de la ciencia médica ${ }^{1}$, la conducta del profesional médico en cuestión no permite que, antes del transcurso del plazo legalmente fijado para interrumpir voluntariamente el embarazo, o antes de la concepción, los progenitores conozcan de los males que afectan o amenazan a su descendencia futura, lo que podría haberles permitido, según el caso, adoptar una decisión sobre si concebir o no o sobre si interrumpir o no el embarazo en curso para evitar el naci-

${ }^{1}$ Si existiera una cura o remedio al mal o defecto que padece el embrión o feto, el comportamiento de los profesionales médicos intervinientes que no detectan el problema, ni permiten, por tanto, ponerle solución sería equiparable a una causación del daño por omisión. La enfermedad o defecto es causada por los profesionales sanitarios, en la medida en que su comportamiento no permitió que se evitara. 
miento del niño enfermo. Por tanto, bien por la ausencia de diagnóstico o bien por la comunicación de un "falso negativo", los progenitores quedan privados de una información fundamental y necesaria para la adopción de decisiones respecto de su procreación futura.

Pues bien, cuando se concreta el riesgo del que no se advirtió y se produce el nacimiento de un niño que padece un grave defecto o enfermedad, surge la pretensión de reclamar una indemnización de responsabilidad civil por estos hechos por parte de los posibles damnificados: los progenitores (ambos o sólo la gestante, según el supuesto de hecho) y el propio niño. La reclamación de los progenitores -denominada, responsabilidad por wrongful birth- se centra, fundamentalmente, en las consecuencias que tiene el diagnóstico erróneo sobre sus derechos e intereses por razón del nacimiento de su hijo; la del niño -ejercitada en su nombre y denominada acción de responsabilidad por wrongful life- se centra en el daño que le supone el hecho de que se le haya permitido nacer en esas condiciones enfermas; en definitiva, el hecho de vivir.

El origen de este tipo de reclamaciones asociadas a la vida se suele remontar a un caso estadounidense (Zepeda vs. Zepeda), de 1963, en el que se planteaba un supuesto algo diferente. Se trataba de la demanda interpuesta por un hijo frente a sus padres por el daño que le suponía el hecho de haber nacido en unas circunstancias familiares o sociales poco idóneas -concretamente, bajo el estigma de la ilegitimidad-y por haberse visto privado de una infancia normal en un hogar normal. La demanda fue desestimada, pero no tanto porque no existiera en este caso un daño susceptible de ser reparado, sino, más bien, por el riesgo que suponía abrir las puertas a este tipo de reclamaciones contra los padres ${ }^{2}$. Las puertas, sin embargo, quedaban abiertas a la calificación de la vida como daño en otros contextos diferentes, oportunidad que, con el tiempo, se ha ido concretando en el surgimiento paulatino de diversos tipos de reclamaciones de responsabilidad civil que tienen que ver con el inicio de la vida ${ }^{3}$. Entre ellas se cuentan las acciones de wrongful birth y wrongful life, en las que, al igual que en el caso Zepeda $v s$. Zepeda, la demanda se centra en el hecho de haber nacido el niño en condiciones desventajosas -gravemente enfermo, en este caso-, pero en

${ }^{2}$ En palabras del tribunal: "Encouragement would extend to all others born into the world under conditions they might regard as adverse. One might seek damages for being born of a certain colour, another because of race; one for being born with a hereditary disease, another for inheriting unfortunate family characteristics; one for being born into a large and destitute family, another because a part has an unsavoury reputation". Un estudio de esta demanda y de sus argumentos, en Morris Ploscowe, "An action for wrongful life", in New York University Law Review, No 38, New York, 1963, pp. 1.078-1.080.

${ }^{3}$ Una panorámica general de todas las acciones de responsabilidad civil relacionadas con el comienzo de la vida se puede encontrar en la voz "Responsabilidad perinatal", de la Enciclopedia de Bioderecho y Bioética, 2008 (en prensa). 
las que la reclamación no se dirige frente a los progenitores -que aparecen aquí también como víctimas, junto al niño nacido enfermo-, sino frente a los profesionales sanitarios cuyo comportamiento no permitió impedir el nacimiento en estas condiciones de enfermedad para el niño.

Antes de entrar a analizar con mayor detención en qué consisten estas acciones de responsabilidad civil, para comprender a cabalidad la problemática que suscitan, considero necesario hacer una breve referencia al contexto en el que surge la idea de plantear ante los tribunales este tipo de demandas en las que la vida se califica de daño jurídicamente indemnizable. Para entender este fenómeno se ha de tener en cuenta el desarrollo progresivo de la responsabilidad civil a lo largo del siglo xx y el incremento paralelo de las reclamaciones a los profesionales sanitarios por responsabilidad civil. Así, en la actualidad, diversos cambios socioeconómicos han propiciado que se haya visto alterada la imagen social de la responsabilidad civil y de su función en el ordenamiento jurídico, y que se pretenda que sirva para reparar cualquier revés o contrariedad que experimente un individuo, sea o no atribuible a un comportamiento culpable de otro ${ }^{4}$. Así, desde el momento en que una persona experimenta o cree experimentar un perjuicio en sus intereses personales o patrimoniales se busca de inmediato un sujeto al que reclamarle una indemnización por el mismo ${ }^{5}$. Esto redunda en una ampliación -no siempre aceptada por la doctrina y la jurisprudencia- del concepto de daño, en el que se intenta que tengan cabida hechos o fenómenos que hasta no hace demasiado resultaba inimaginable que se calificasen de perjudiciales. Uno de ellos es el hecho mismo de la vida -fundamentalmente, el inicio de la vida-, que en el contexto de esta evolución de la responsabilidad civil se pretende calificar como daño cuando se trata de una vida no deseada, bien por no planeada (como en el caso de las llamadas acciones de wrongful conception) o, bien, como en el caso aquí estudiado, por las condiciones enfermas en que se encuentra su titular.

${ }^{4}$ La educación científica, la progresiva secularización de la población o el abandono de los conceptos vitales fatalistas, son algunos de los factores que han propiciado en muchos países este paulatino cambio de la mentalidad social, que centra su atención en la necesaria reparación del daño sufrido por la víctima. Como señala Luis Díez-PicAzo, "La responsabilidad civil hoy", en Anuario de Derecho civil, vol. 32, No 4, Madrid, 1979, p. 728, la conciencia imperante en la época de la Codificación, conforme a la cual el daño se veía como un castigo de Dios por los pecados cometidos o como prueba del temple del alma de la víctima, cambia a raíz de la Revolución Industrial, de manera que la indemnización se impone, como una exigencia ineludible, para cubrir la necesidad de otorgar una protección y una defensa más vigorosa a la persona.

${ }^{5}$ Véase Mariano YzQuierdo Tolsada, "La responsabilidad civil ante el nuevo milenio: algunas preguntas para el debate”, en Ricardo de Ángel YágüEZ y Mariano YzQUierdo Tolsada (coords.), Estudios de responsabilidad civil en homenaje al Prof. Roberto López Cabana, Madrid, Dykinson, 2001, p. 232. 
Como no podía ser de otra forma, los médicos y demás profesionales sanitarios son uno de los sectores más afectados por esta búsqueda constante de un responsable para cualquier perjuicio que sufra un sujeto, ya que la actividad que desarrollan, en la que se pone en juego de forma directa la vida, la salud y la integridad física de los pacientes, es una fuente potencial de daños que recaen sobre bienes de importancia fundamental. El contexto de una atención médica masificada y, en muchas ocasiones, despersonalizada, en la que no se crean verdaderas relaciones de confianza entre el paciente y el médico, contribuye a incrementar el clima de descontento y desconfianza de los pacientes hacia los médicos ${ }^{6}$. Por ello, aunque la curación no siempre sea científica o técnicamente posible, es frecuente, tal y como se está produciendo en la actualidad la evolución de la responsabilidad civil, que el paciente que no resulte curado por el profesional sanitario se vuelva contra éste -desaparecido ya todo temor reverencial al médico-y le reclame una indemnización por el daño que le supone el deterioro de su salud, sea o no causado por el médico.

Éste es el contexto que explica el surgimiento de las acciones de wrongful birth y wrongful life: cuando se produce el nacimiento de un niño gravemente enfermo o discapacitado por causas naturales, ante la imposibilidad de pedir responsabilidad a otros sujetos, las miradas se vuelven hacia los profesionales sanitarios que participaron en el proceso de seguimiento del embarazo o de diagnóstico previo al mismo (si hubo un previo diagnóstico preconceptivo), buscando atribuirles algún tipo de responsabilidad por el hecho del nacimiento en tales condiciones. Aunque la enfermedad o discapacidad no haya sido causada por el comportamiento del profesional sanitario, el hecho de que no se haya ofrecido la posibilidad de impedir el nacimiento, y que, consiguientemente, llegado a término el embarazo haya nacido un niño en graves condiciones de salud, es el daño sobre el que se estructura la reclamación de los progenitores y del niño.

Sin embargo, hay que afirmar desde un primer momento que esta pretensión no tiene por qué concretarse necesariamente en una indemnización derivada de la aplicación de la responsabilidad civil, pues, aunque la imagen social de esta institución esté cambiando y, aunque estemos asistiendo a un clima de constante incremento de reclamaciones a los profesionales sanitarios, por regla general este cambio no se ha traducido aun en una reforma de la responsabilidad civil que le lleve a asumir esa función cuasiasistencial o de reparación de cualquier perjuicio que parece pretender la sociedad actual, ni se ha traducido en una obligación de los

${ }^{6}$ Véase al respecto, entre otros muchos, el análisis de Manuel GARCíA BLÁZQUEZ y Juan José Molinos Сово, Manual práctico de responsabilidad y defensa de la profesión médica (Aspectos jurídicos y médico-forenses), Granada, Comares, 1995, pp. 12-15. 
médicos y demás profesionales sanitarios de responder por todo daño que experimenten sus pacientes. Por ello, aunque los protagonistas de las acciones de wrongful birth y wrongful life pretendan encontrar en todo caso como responsables de sus desdichas a los profesionales médicos, esta responsabilidad sólo se les podrá imputar en forma efectiva cuando estén presentes los presupuestos de la responsabilidad civil. Dicho de otra forma, no todo nacimiento de un niño enfermo o gravemente discapacitado va a dar lugar a una responsabilidad de los profesionales médicos intervinientes, sino sólo aquellos supuestos en los que concurran los requisitos necesarios para traspasarles a éstos la carga del daño experimentado por los progenitores o el niño nacido enfermo.

Lo que se va a analizar a continuación es: cuáles son estos presupuestos y, por tanto, en qué contexto debe prosperar una reclamación de responsabilidad por wrongful birth o wrongful life.

\section{Presupuestos de LAS ACCIONES DE WRONGFUL BIRTH Y WRONGFUL LIFE}

Como se deduce de lo expuesto, el argumento que sirve de base a la reclamación frente a los profesionales sanitarios en estos casos no es que el responsable haya causado el defecto o enfermedad que padece el niño, sino que no advirtió de dicho mal a sus progenitores y que no permitió que se impidiera el nacimiento de forma legal. Esto pone de relieve que la posibilidad de que se plantee en un determinado ordenamiento una demanda de wrongful birth o de wrongful life depende de la existencia de dos presupuestos. En primer lugar, sólo puede plantearse este tipo particular de reclamaciones de responsabilidad si, en el ordenamiento que resulte aplicable, está contemplada la facultad de interrupción voluntaria del embarazo como una opción lícita de la que disponen la gestante o ambos progenitores; en segundo lugar, es necesario que, en el caso concreto, el mal o defecto que padece el niño, posteriormente nacido, pudiera ser detectado o diagnosticado de acuerdo con el estado de la ciencia médica, antes de la concepción o antes del plazo legalmente fijado para el ejercicio de la facultad de interrupción voluntaria del embarazo. Sin el primer presupuesto, no es posible hablar siquiera de una acción de wrongful birth o de wrongful life-al menos, no respecto de los posibles falsos negativos en el contexto de diagnósticos prenatales-, sino que se trataría de otro tipo de demandas de responsabilidad civil en las que se plantearía una problemática distinta ${ }^{7}$; sin el segundo presupuesto, aunque

${ }^{7}$ En este sentido, Miquel Martín Casals y Josep Solé Feliú, "Sentencia del Tribunal Supremo de 7 de junio de 2002”, en Cuadernos Civitas de Jurisprudencia Civil, No 60, Navarra, 
el caso concreto se encuadre dentro de la tipología de casos agrupados bajo esta terminología, no puede afirmarse la responsabilidad civil de los profesionales sanitarios intervinientes. Veamos cada uno de los presupuestos por separado, para explicar estas afirmaciones.

De acuerdo con el primer presupuesto, es necesario partir de una precisión sobre lo que se indicó en un principio, sin hacer suficiente hincapié sobre ello. Concretamente, ha de señalarse que este tipo de demandas de responsabilidad pueden plantearse en dos contextos diferentes: uno es el de los diagnósticos preconceptivos (antes de la concepción, un sujeto o una pareja acude de forma voluntaria a un profesional sanitario -en el contexto, fundamentalmente, del diagnóstico genético-, a fin de averiguar si existen riesgos que amenacen a su futura descendencia, y, pese a los indicios presentes en el paciente, no se le advierte de la existencia de enfermedades de tipo genético, hereditario o, en general, transmisible, que pueden afectar el desarrollo del futuro ser) y el otro es el de los diagnósticos prenatales (durante el seguimiento de un embarazo, no se informa a la gestante $-\mathrm{o}$, en general, al titular o titulares de la facultad de interrupción voluntaria del embarazo- de la enfermedad o mal que padece el embrión o feto, o se le informa de que éste se encuentra en perfectas condiciones de salud). En el primero de los casos, el comportamiento del profesional sanitario impide que los progenitores dispongan de toda la información relevante para decidir libremente si concebir o no; en el segundo, en cambio, el comportamiento del profesional impide al titular de la facultad de interrupción voluntaria del embarazo adoptar una decisión al respecto. Pues bien, en la mayoría de los ordenamientos jurídicos la decisión acerca de la procreación está reconocida como una libertad de la que gozan los individuos ${ }^{8}$. Por este motivo, ha de afirmarse que en la mayoría de los ordenamientos podrían llegar a plantearse -si aún no se han planteado- demandas por wrongful birth o wrongful life en el contexto de un falso negativo en el diagnóstico preconceptivo.

Sin embargo, no en todos los ordenamientos está reconocida la facultad de interrupción voluntaria del embarazo. En algunos -como es el caso de Irlanda o de Chile-, esta facultad no está reconocida en ningún caso; en otros -caso de España, Francia o Alemania-, está reconocida sólo para ciertos motivos o indicaciones que se han de hacer valer por el titular de esta facultad, dentro -o no- de un plazo determinado; finalmente, en

2002, pp. 1.115-1.116, consideran "subsidiaria" esta acción, que queda "fuera del supuesto típico de wrongful birth" (p. 1.118).

${ }^{8}$ Como ponen de relieve Jean-Louis Baudouin y Catherine Labrusse-Riou, Produire l'homme: de quel droit? Étude juridique et éthique des procréations artificielles, Paris, PUF, 1987, p. 150, los Estados ensayan políticas de incentivación o desincentivación de la procreación (según sus necesidades), pero no crean obligaciones positivas y directas de procrear o no procrear, pues es imposible imponer tal obligación. 
otros ordenamientos -como es el caso paradigmático de Estados Unidos-, la facultad de interrupción del embarazo está reconocida de forma libre, sometida sólo a una limitación de plazos. Pues bien, la posibilidad de que se plantee una demanda de wrongful birth o de wrongful life en el contexto de un "falso negativo" en un diagnóstico prenatal -esto es, por un error de diagnóstico producido durante el seguimiento del embarazo- va asociada al reconocimiento en el ordenamiento en cuestión de la facultad de interrupción del embarazo, bien de forma libre, bien, al menos, para el motivo denominado "embriopático o eugenésico" -es decir, para el caso de que se detecten graves defectos o enfermedades físicas o síquicas en el embrión o feto-, ya que sólo en estos casos puede afirmarse que el comportamiento del profesional sanitario priva al designado como titular de la facultad de interrupción voluntaria del embarazo de la información relevante a la hora de adoptar su decisión. En cambio, en aquellos otros ordenamientos en que no esté reconocida esta opción para las gestantes o para los progenitores, o en los que esté reconocida, pero sólo para supuestos diferentes (v.gr., el caso de Italia, donde el aborto voluntario sólo se permite para el supuesto de peligro para la salud física o síquica de la gestante $\left.{ }^{9}\right)$, la omisión de información sobre el estado de salud de la descendencia ya concebida no priva a la gestante o a los progenitores de facultad alguna sobre la que estructurar una demanda de responsabilidad civil como las aquí planteadas. De hecho, en estos casos desaparece por completo la posibilidad de interponer una reclamación por wrongful life, ya que la pretensión del niño, de que sufre un daño porque no se le impidió nacer, carece de base -al no existir legalmente la opción de impedir tal nacimiento-, y la reclamación de los progenitores se transforma en algo distinto (v.gr., en la reclamación del daño sufrido por no haberse podido preparar para el nacimiento de un niño afectado de enfermedades o defectos ${ }^{10}$ ), con una problemática diferente y menos conflictiva que la que presentan las acciones de wrongful birth ${ }^{11}$.

${ }^{9}$ No es suficiente, pues, con el reconocimiento de la facultad de aborto para otros motivos, ya que, en tal caso, el hecho de que existieran defectos o malformaciones en la descendencia futura no permitiría a los progenitores decidir acerca del ejercicio de la facultad de aborto; aunque el diagnóstico fuera correcto, no produciría una privación de esta facultad de interrupción del embarazo, y el problema que se plantearía sería otro. Así lo reconoce la sentencia de la Corte de Cassazione de 24 de marzo de 1999.

${ }^{10}$ En este sentido, por ejemplo, la sentencia del Tribunale di Perugia de 7 de septiembre de 1998, concedió una indemnización por la falta de preparación sicológica de los progenitores que habían recibido una información errónea durante el embarazo sobre el estado de salud del niño que habían concebido. Se suma a esta valoración Mario Conte, "Dovere d'informazione e danno biologico: uno strano connubio", in Diritto di Famiglia e delle Persone, anno, xxiv, vol. 2, No 1, Milano, 1995, p. 672, que incluye estos supuestos dentro de los de danno biologico.

${ }^{11}$ Los tribunales italianos, sin embargo, no siempre han tenido en cuenta el presupuesto aquí señalado. De hecho, en Italia se han planteado varios casos de responsabilidad por 
En cuanto al segundo de los presupuestos señalados -que el mal o defecto que padece el niño pudiera haber sido detectado en fase preconceptiva o prenatal, de acuerdo con el estado de la ciencia médica-, permite hacer dos observaciones. La primera es que la existencia de las acciones de wrongful birth y wrongful life, así como su extensión y evolución van inextricablemente asociadas al avance de la ciencia médica; en particular, al avance del diagnóstico preconceptivo -fundamentalmente, genético-y prenatal. Sin duda, el avance de la ciencia en el ámbito del diagnóstico genético y el diagnóstico prenatal ha hecho surgir nuevas pretensiones de los pacientes en relación con la información de que pueden disponer y sobre la que pueden adoptar decisiones respecto de la descendencia futura. Lo que antes no era posible, ahora lo es; y, asimismo, lo que antes no era considerado un daño -por ser imposible de evitar-, ahora puede serlo ${ }^{12}$. De esta forma, se puede afirmar: a medida que aumente el desarrollo científico y técnico, se irá incrementando el número de enfermedades o defectos que puedan ser detectados en las fases previas al nacimiento y sobre los que, deberá informarse a los progenitores que se sometan a un diagnóstico preconceptivo o prenatal, a fin de que puedan adoptar las decisiones pertinentes.

Ahora bien, este segundo presupuesto al que ahora nos referimos hace referencia a otro condicionante necesario para que concurra plenamente el supuesto de hecho de las acciones de wrongful birth y wrongful life. En concreto, la exigencia de que el mal o defecto que padece el niño fuera detectable en fase preconceptiva o prenatal permite hacer una segunda observación que tiene que ver con el comportamiento que ha de haber desarrollado el profesional sanitario del que se exige responsabilidad para que se le pueda imputar efectivamente la obligación de indemnizar en este contexto. En este sentido, ha de partirse de la afirmación de que la responsabilidad de estos profesionales intervinientes en el diagnóstico preconceptivo o prenatal debe ir asociada a la culpa o negligencia en la emisión del diagnóstico preconceptivo o prenatal: no se informó a la gestante o a los progenitores del mal o defecto que padecía el embrión o feto, o que amenazaba a la descendencia futura, pudiendo, sin embargo, haberse informado del mismo, de acuerdo con la lex artis. Así, para poder imputar la responsabilidad en este contexto a alguno o algunos de los médicos o demás intervinientes

wrongful birth y wrongful life en relación con fallos de información sobre el estado de salud del embrión o feto. Por poner un ejemplo, ha de citarse la sentencia del Tribunale di Bergamo de 2 de noviembre de 1995.

${ }^{12}$ Así sostiene Edward Picker, "Schadensersatz für das unerwünschte Kind (Wrongful birth). Medizinischer Fortschritt als zivilisatorischer Rückschritt?", in Archiv für die civilistische Praxis, No 195 , Tübingen, 1995, p. 485, que cada avance de la ciencia o técnica se transforma inmediatamente en una correspondiente pretensión jurídica. 
en el proceso de diagnóstico, es necesario que se constate que actuaron de modo negligente en alguna de las fases de la prestación sanitaria, de manera que ese comportamiento impidiera la formulación de un diagnóstico certero. Por el contrario, cuando la enfermedad o defecto que se concrete tras el nacimiento sea una de las que, de acuerdo con el estado actual de la ciencia médica, no pueda ser diagnosticada antes de la concepción o antes del plazo legalmente fijado para ejercitar la facultad de interrupción voluntaria del embarazo, nada se le puede reprochar al profesional sanitario que no la detectara en fase preconceptiva o prenatal; su diagnóstico, aunque erróneo, se enmarcaría en el contexto de un comportamiento diligente ${ }^{13}$, lo que excluye la responsabilidad civil en la mayoría de los ordenamientos ${ }^{14}$. De nuevo, se trataría de un supuesto en que carecería de base la acción de wrongful life y en el que la acción de wrongful birth se transformaría en una reclamación diferente a la aquí planteada.

Para apreciar la negligencia de dichos profesionales, ha de acudirse, por tanto, al parámetro de la lex artis en el estado actual de la ciencia médica, pues es el que permite determinar en qué medida habría sido posible que los progenitores que no reciben información, o reciben una información incorrecta, habrían podido obtener un diagnóstico correcto antes de la concepción o en el plazo que, en su caso, se establezca para el ejercicio de la facultad de aborto. Los indicios presentes en ambos progenitores ${ }^{15}$, el

${ }^{13}$ El error del diagnóstico no es incompatible con un comportamiento diligente del profesional sanitario, ya que la diligencia se valora de acuerdo con el parámetro de conducta que ofrece la lex artis ad hoc y ésta, a su vez, se nutre de los saberes y técnicas conocidos, aplicados y acumulados por los profesionales sanitarios en un determinado momento. La ciencia médica, sin embargo, tiene sus límites y por ello es posible que un profesional, actuando de acuerdo con la lex artis ad hoc, no pueda emitir un diagnóstico que se corresponda con la situación real del paciente. Por ello, en un contexto en que la responsabilidad se imputa a partir de un criterio de culpa, como es el caso, esta imputación sólo se produce ante la concurrencia de tal criterio y no por la mera existencia de un error médico. Véase, por todos, Joaquín AtAz López, Los médicos y la responsabilidad civil, Madrid, Montecorvo, 1985, p. 313.

${ }^{14}$ En la medida en que el sistema de responsabilidad civil se guíe por parámetros objetivos en la imputación subjetiva, el hecho de que un determinado defecto o enfermedad no sea detectable de acuerdo con el estado actual de la ciencia médica excluye este evento del ámbito de control del posible responsable y, con ello, de una posible reclamación. Aunque la cuestión es discutible, podría equipararse este supuesto al de fuerza mayor, que en la mayoría de los ordenamientos excluye la imputación subjetiva de responsabilidad; lo contrario sería equiparar la responsabilidad civil a un sistema asistencial.

${ }^{15}$ Así, por ejemplo, el profesional médico que no informara a unos futuros progenitores de que eran portadores de la enfermedad de Tay-Sachs no habría obrado negligentemente si no constaran antecedentes de que aquéllos procedieran o tuvieran ascendencia del Este de Europa, pues se trata de un desorden genético originario de dicha región. Del mismo modo, en el contexto de un diagnóstico prenatal, han de tenerse en cuenta una serie de factores que determinan la 
estado de desarrollo actual de la ciencia médica en materia de diagnóstico genético, preconceptivo o prenatal en el país concreto en el que se plantee la reclamación de responsabilidad ${ }^{16}$, así como los límites derivados de las circunstancias económicas aplicadas a los servicios sanitarios ${ }^{17}$, servirán para definir cuándo el mal o defecto del niño era detectable a tiempo de permitir la correspondiente decisión de los progenitores y cuándo, consiguientemente, era deber del médico informar sobre él, resultando "erróneo" el diagnóstico que no incluye tal información.

Por otra parte, como se ha indicado, este comportamiento negligente sobre el que se puede imputar la responsabilidad civil al profesional sanitario puede producirse en cualquiera de las fases del diagnóstico -desde la fase inicial de anamnesis hasta la de comunicación al paciente del diagnóstico-, puesto que cualquiera de los pasos previos al diagnóstico puede ser el que determine el error final del mismo. La consecuencia de esta afirmación -no siempre puesta con suficiente relieve- es que la responsabilidad en este contexto puede reclamarse de cualquiera de los profesionales sanitarios intervinientes en el proceso de diagnóstico preconceptivo o prenatal (v.gr., enfermeros, especialistas en ecografía, etc.) y no sólo contra los médicos especialistas en ginecología que intervengan en el seguimiento del embarazo ${ }^{18}$.

calificación del embarazo como "embarazo de riesgo", lo que aconseja un seguimiento más exhaustivo. Para mayores referencias sobre estos factores de riesgo, véase Aitziber EMALDI Cirión, El consejo genético y sus implicaciones jurídicas, Bilbao-Granada, Publicaciones de la Cátedra de Derecho y Genoma Humano y Editorial Comares, 2001, pp. 46-49.

${ }^{16}$ Es una realidad en que no existe un mismo nivel de conocimientos científicos o de dotación instrumental en países desarrollados y en países subdesarrollados -ni siquiera entre distintas zonas de un mismo Estado (v.gr., rurales y urbanas)-, motivo por el cual es posible que el parámetro de diligencia varíe de un lugar a otro; en este sentido, véase Mariano Alonso Pérez, "La relación médico-enfermo, presupuesto de responsabilidad civil (en torno a la lex artis)", en Juan Antonio Moreno Martínez (coord.), Perfiles de la responsabilidad civil en el nuevo milenio, Madrid, Dykinson, 2000, pp. 38-39. En consecuencia, cuanto mayor sea el grado de desarrollo del lugar en que se lleve a cabo el diagnóstico preconceptivo o prenatal, mayor será la diligencia exigible a los profesionales sanitarios para la detección de los defectos o males de la futura descendencia.

${ }^{17}$ Los factores económicos determinan en muchas ocasiones el nivel de atención que puede ser dispensado de hecho al paciente, o el material e instrumental exigible para cada profesional sanitario. La escasez de recursos impide, en la práctica, la aplicación a todos los pacientes del conjunto de remedios o técnicas existentes en el acervo de conocimientos que integran la lex artis. Ello redunda en el comportamiento que se puede exigir de los profesionales sanitarios. No obstante, ha de alcanzarse un equilibrio entre estos condicionantes y la adecuada atención a los pacientes. Véase a este respecto mi monografía, La responsabilidad por los diagnósticos preconceptivos y prenatales. Las llamadas acciones de wrongful birth y wrongful life, Valencia, Tirant lo Blanch, 2005, pp. 280-285.

${ }^{18}$ Así lo puse de relieve en un trabajo anterior. Véase a este respecto el comentario a la "Sentencia del Tribunal Supremo de 18 de diciembre de 2003, en Cuadernos Civitas de Jurisprudencia Civil, № 66, Navarra, 2004, pp. 1.030-1.033. 


\section{TRATAMIENTO QUE HAN RECIBIDO ESTAS ACCIONES}

DE RESPONSABILIDAD CIVIL MÉDICA

Las acciones de responsabilidad por wrongful birth y wrongful life pueden plantearse en todos los ordenamientos en los que se reúnan los presupuestos señalados. De hecho, el número de países en los que se han producido reclamaciones de este tipo ha ido aumentando progresivamente. A partir de un temprano inicio en Estados Unidos, en el año 1967 (caso Gleitman vs. Cosgrove $)^{19}$, su aparición en otros países es más tardía, pero acaba produciéndose igualmente hacia los años ochenta. Así, ocurre, al menos, en Alemania, Francia, Inglaterra e Italia. Varios años después, a mediados de los años noventa, se incorpora a esta lista España, donde, pese a su tardía incorporación, el número de casos de wrongful birth y wrongful life ha crecido en forma extraordinaria en los últimos años, existiendo ya más de diez sentencias del Tribunal Supremo en las que se tratan este tipo de pretensiones.

En todos los ordenamientos en que se han planteado estas demandas, la reclamación de responsabilidad civil se ha tenido que enfrentar a diversos argumentos de corte más bien ético o moral que netamente jurídico, lo que ha entorpecido su admisión así como su estudio; no en vano, detrás de cada una de estas acciones de responsabilidad se encuentra la idea de que es mejor no vivir que vivir en las condiciones en que se encuentra el niño: en definitiva, la reclamación de los padres se centra en que no se ha podido impedir el nacimiento de su hijo (ya que no era posible que naciera sano) y la del niño, directamente, en que habría preferido no nacer, pretensiones, en ambos casos, que parecen chocar de fronte con la protección de la vida y su reconocimiento como bien jurídico digno de protección en la mayoría de los ordenamientos. A partir de esta idea, se puede afirmar que las convicciones personales o religiosas se opondrán siempre de forma tajante al reconocimiento de este tipo de demandas, que otros mirarán con mucho recelo ${ }^{20}$.

Este rechazo se ha manifestado, en ocasiones, a través del argumento de que la responsabilidad civil no es la vía más adecuada para solventar el

${ }^{19}$ Se negó la indemnización por wrongful birthy wrongful life en el caso de un niño afectado de diversas malformaciones producidas como consecuencia de la rubéola contraída por su madre durante el embarazo, respecto de la cual se había informado a la progenitora que no tendría consecuencias sobre el feto. La corte de Nueva Jersey se basó en dos razonamientos para rechazar la demanda de wrongful life: por un lado, no se podían comparar lógicamente la enfermedad con el vacío completo de la no existencia; por otro lado, aunque los daños fueran calculables, era de orden público el mantenimiento del bien vida. Para la demanda de wrongful birth, el razonamiento se apoyó en la dificultad de medir el daño.

${ }^{20}$ Véase al respecto Harvey TEFF, "The action for wrongful life in England and the United States", in International and Comparative Law Quarterly, vol. 34, Cambridge, 1985, p. 434. 
problema al que se enfrentan los progenitores o el niño involucrados en este contexto. Así, por un lado, se sugiere que existen otras vías diferentes para satisfacer las pretensiones de los progenitores y del niño; en concreto, se señala que lo pertinente aquí sería acudir a prestaciones públicas ${ }^{21}$, argumento que, no obstante, se enfrenta a la dificultad que conlleva la insuficiencia de tales ayudas públicas o su propia inexistencia en algunos ordenamientos $^{22}$. Por otro lado, se argumenta -sobre todo respecto de la acción de responsabilidad por wrongful birth- que la concesión de indemnización a los progenitores de un daño patrimonial por los gastos de mantenimiento del niño supone relevarles de su deber de alimentos frente a éste, que queda trasladado al responsable a través de la indemnización ${ }^{23}$. El efecto de este traslado -se dice- es doblemente pernicioso: por un lado, la responsabilidad civil se inmiscuye en el ámbito propio del Derecho de Familia ${ }^{24}$; por otro, se altera lo dispuesto por las normas sobre alimentos entre parientes, que tienen un carácter imperativo. Por ello, este razonamiento aconseja no aplicar la institución de la responsabilidad a este tipo de problemas. Sin embargo, es discutible, pues parte del presupuesto de que efectivamente sean indemnizados, como daño patrimonial de los progenitores, los gastos de alimentos del niño enfermo -lo cual ya es de por sí dudoso- y requiere, además, aceptar que la indemnización sea equivalente al cumplimiento de la obligación de alimentos y que exonere a los progenitores de dicha obligación, lo que choca con la distinta naturaleza y presupuesto de ambas instituciones ${ }^{25}$.

${ }^{21}$ De hecho, ésta parece ser la solución a la que se ha llegado en Francia a través de la ley 2002-303 de 4 de marzo cuando remite la compensación del niño nacido en condiciones enfermas a la solidarité nationale (artículo 1.I). Asimismo, en Alemania, señala Thomas Winter, "Leben als Schaden? Vom Ende eines französischen Sonderwegs", in Juristen Zeitung, N $^{\circ} 7$, Tübingen, 2002, p. 332, que, si lo que preocupa es el bienestar del niño discapacitado, tal preocupación corresponde al Estado, que se ha de ocupar en general de los sujetos discapacitados a través de sus instituciones sociales.

${ }^{22}$ Así, Amos SHapira, “Wrongful life lawsuits for faulty genetic counselling: should the impaired newborn be entitled to sue?", in Journal of Medical Ethics, $\mathrm{N}^{\circ}$ 24, London, 1998, p. 371 , critica esos argumentos, que no son compatibles con los sistemas en que no se conoce este principio de solidaridad social, como es el caso del de Estados Unidos.

${ }^{23}$ Véase a este respecto, entre otros, Winifred Lankers, "Zur Abwälzung von Unterhaltskosten”, in Zeitschrift für das gesamte Familienrecht, No 7/8, Regensburg 1969, pp. 386 y 388.

${ }^{24}$ Martín Casals y Solé Feliú (n. 7), pp. 1.103-1.104, destacan que la concesión de una indemnización por los alimentos incide en la coherencia interna de los principios básicos sobre los que se asienta el Derecho de Familia. Se rompe el principio de solidaridad familiar y se quiebra la lógica interna del sistema. La contradicción con el Derecho de Familia es también señalada por Kathleen GaLLaGHer, "Wrongful life: should the action be allowed?", in Louisiana Law Review, N 47, Louisiana, 1987, p. 1.330. 88-92.

${ }^{25}$ Respecto de estos argumentos y su contestación, véase mi monografía (n. 17), pp. 
En otras ocasiones, el estudio de estas acciones y su rechazo o aceptación se ha justificado a través de argumentos que, en realidad, tienen más que ver con la propia ideología del jurista o del tribunal, que con la aplicación estricta de la responsabilidad civil y el análisis de la concurrencia de sus elementos en este tipo de supuestos. La estrecha relación entre la reclamación de responsabilidad civil y el hecho de la vida pone de relieve la existencia de un importante componente ético o moral en estas acciones de wrongful birth y wrongful life que decide en muchas ocasiones el tratamiento que reciben y la aplicación de soluciones que no atienden tanto a los principios y valores reconocidos e integrados en el ordenamiento como a las propias convicciones personales ${ }^{26}$. Así, a favor del reconocimiento de estas demandas juegan, en ocasiones, criterios de justicia material, que abogan por la satisfacción de los que se han visto perjudicados por un comportamiento negligente; tal es el caso de los argumentos que aluden a la penosa situación en que se encuentra el niño o a la necesidad de salvaguardar o garantizar su posición ${ }^{27}$. Frente a ello, en contra de este tipo de acciones intervienen convicciones éticas y religiosas que destacan por encima de todo el valor de la vida y la imposibilidad de calificarla como daño ${ }^{28}$ y que tratan de enmascararse bajo argumentos seudojurídicos; así, se afirma que la reclamación de una indemnización por estos eventos puede causarle un trauma al niño y lesiona su dignidad como persona ${ }^{29}$, que la concesión de una indemnización

${ }^{26}$ Según José Enrique Bustos Pueche, "Un caso de voluntarismo judicial: la sentencia del Tribunal Supremo de 6 de junio de 1997”, en La Ley, No 5, D-250, Madrid, 1997, p. 1700: "la particular ideología del juez, al poner una sentencia (...) desempeña un papel relevante y que puede ser determinante, si la materia objeto de la sentencia no es de naturaleza estrictamente técnica sino que, además, está entreverada de sustancia moral, ético o política". La misma idea se encuentra presente entre ciertos autores extranjeros, como el francés Laure FInEL, "La responsabilité du médecin en matière de diagnostic des anomalies foetales", in Revue Trimestrielle de Droit Sanitaire et Social, vol. 33, No 2, Paris, avril-juin 1997, pp. 225 y 238 o el italiano Michele DAssio, "Il principio di irrisarcibilità della nascita indesiderata nell'ordinamento francese", en Antonio D'Angelo (dir.), Un bambino non voluto è un danno risarcibile?, Milán, Giuffrè Editore, 1999, p. 115. Entre los anglosajones, destaca especialmente la opinión de Alexander Morgan CAPron, "Tort liability in genetic counseling", in Columbia Law Review, N 79, New York, 1979, p. 650: "courts are not announcing purely rational conclusions (...) but are instead proclaiming their personal views on certain value-laden facts".

${ }^{27}$ Son paradigmáticas en este sentido las palabras de la sentencia del caso Curlender v. Bio-Science Laboratories: "the reality of the wrongful life concept is that such a plaintiff both exists and suffers, due to the negligence of others". Respecto a este tipo de argumentos, véase mi monografía (n. 17), pp. 114-118.

${ }^{28}$ Ejemplo de ello es el tratamiento de estas acciones por parte de Therese LySAUGHT, "Wrongful life? The strange case of Nicholas Perruche", in Commonweal, No 129, New York, 2002, p. 11.

${ }^{29}$ Así, Lankers (n. 23), p. 388 o Picker (n. 12), pp. 524-525. 
muestra un cierto matiz de desprecio hacia la situación de discapacitados que trae reminiscencias de las teorías fascistas, hitlerianas y orwellianas de pureza de la raza ${ }^{30}$, o que la aceptación de este tipo de demandas puede llevar a la práctica de una medicina defensiva por parte de los profesionales afectados ${ }^{31}$, así como a la extensión sin límite del uso de la responsabilidad civil para otro tipo de daños asociados al inicio de la vida ${ }^{32}$.

Todos ellos aportan una visión extrajurídica a las acciones de wrongful birth y wrongful life poco acorde con una cuestión que pretende ser resuelta conforme a Derecho Positivo. Si bien las propias convicciones pueden mover al jurista a buscar la solución en un sentido u otro, ahí donde la ley se impone, la propia ideología debe someterse ${ }^{33}$. Por ello, aunque las valoraciones éticas e ideológicas no son del todo ajenas a un estudio de la responsabilidad civil -pues, sin duda, influyen en la propia elaboración del concepto de daño (en la medida en que se reflejen en principios o valores integrados en el ordenamiento)-, no deben convertirse en la única justificación para afirmar o negar la indemnización por el nacimiento del niño en estos casos. Por el contrario, la respuesta a la cuestión de la aplicación de la responsabilidad debe venir del estudio de la concurrencia en ambas acciones de los elementos que tradicionalmente configuran esta institución. Sólo un análisis detenido de éstos puede proporcionar una respuesta definitiva sobre su admisión o rechazo.

${ }^{30}$ Afirma al respecto Sthéphane Alloiteau, "L'arrêt C.H.R. de Nice: l'indemnisation du préjudice lié a un défaut d'information médicale (Conseil d'Etat, 14 février 1997)", in Les Petites Affiches, N $^{\mathrm{O}}$ 64, Paris, 1997, p. 32, que no está muy lejana de la indemnización al niño una política de selección. Opiniones similares pueden encontrarse en Maryse Deguergue, "Les préjudices liés à la naissance", in Responsabilité civile et assurances, No spéciale, Paris, 1998, p. 20 o Anthony JACKSON, "Action for wrongful life, wrongful pregnancy, and wrongful birth in the United States and England", in Loyola of Los Angeles International and Comparative Law Journal, $\mathrm{N}^{\circ}$ 17, Los Angeles, 1995, pp. 607-610.

${ }^{31} \mathrm{Al}$ respecto, es interesante un informe de 1974 de la comisión jurídica en Gran Bretaña (Report on Injuries to the Unborn Child), en el que se decía: "such a case of action, if it existed, would place an almost intolerable burden on medical advisers in their socially and morally exacting role. The danger that doctors would be under subconscious pressures to advise abortions in doubtful cases through fear of an action for damages, is, we think, a real one". Numerosos autores se han hecho eco de estos temores, v.gr., TEFF (n. 20), pp. 439-440 o Dieter WEBER, Arzthaftpflicht für Nachkommenschaftschäden?, Berlín-Heidelberg, Springer Verlag, 1988, pp. 61-70.

${ }^{32}$ Este argumento lo enuncia, por ejemplo, Christian VON BAR, The common european law of torts, Múnich, C.H.Beck, 1998, vol. I, pp. 604-605.

${ }^{33}$ El principio ha de ser, pues, que el juez debe evitar juicios de valor fuera de la cuestión sometida a litigio, como señala Pierre-Yves Gautier, "Les distances du juge. À propos d'un débat éthique sur la responsabilité civile", in La Semane Juridique. Edition Génerale, No 2, I 287, Paris, 10 Janvier 2001, p. 68; únicamente deberá atender a los juicios de valor que hayan sido asumidos por el sistema jurídico. 
Pese a ello, el tratamiento de estas acciones de wrongful birth y wrongful life no siempre se ha visto libre de estas valoraciones éticas o morales. Allí donde éstas tienen menor incidencia -en especial, en la reclamación de responsabilidad por wrongful birth-, existe una mayor predisposición a la aceptación de la reclamación de responsabilidad civil. De hecho, el acogimiento de la reclamación de la gestante o de los progenitores en el contexto aquí expuesto ha sido, en general, favorable en los ordenamientos en los que se han planteado este tipo de acciones; aunque la demanda encierra cuestiones éticas y morales importantes, no son tan graves como las que suscita la acción de wrongful life, motivo por el cual el rechazo que han experimentado ha sido menor. Sin embargo, la aceptación de estas acciones no sólo se justifica en esta valoración extrajurídica sino que tiene, también, una base netamente jurídica, puesto que, desde el punto de vista de la responsabilidad civil, los obstáculos a los que se enfrentan estas demandas -en particular, el problema de la identificación de un daño jurídicamente indemnizable- son menores o más fáciles de superar ${ }^{34}$; la posibilidad de distanciar el daño reclamado del hecho de la vida del niño en el caso de la acción interpuesta por uno o ambos progenitores ha resultado, sin duda, a favor de un mayor consenso hacia su aceptación.

182 Por el contrario, ante los mayores obstáculos éticos y jurídicos presentes en las acciones de wrongful life, éstas han sido en general rechazadas en la mayoría de los ordenamientos en los que se han planteado; tal ha sido el caso de Alemania, Inglaterra, Italia y Francia. En este último país, no obstante, hay que destacar que el actual rechazo de estas acciones ha requerido de la intervención específica del legislador, ya que la jurisprudencia, en aplicación de la normativa general sobre la responsabilidad civil, se mostró favorable a la indemnización al niño en el contexto de las acciones de wrongful life a partir del año $2000^{35}$. Sin embargo, tras la ley 2002-303, de 4 de marzo, relative aux droits des malades et à la qualité du système de santé, promulgada ante las protestas de los colectivos de médicos potencialmente afectados por este tipo de reclamaciones de responsabi-

${ }^{34}$ De hecho, allí donde se rechaza este tipo de reclamaciones de responsabilidad civil, la argumentación suele atender más a cuestiones de tipo ideológico que a razonamientos jurídicos. Véase a este respecto, por ejemplo, el caso estadounidense Wilson $v$. Kuenzi.

${ }^{35}$ De hecho, esta indemnización se concedió por primera vez en el famoso caso Perruche (Cour de Cassation, 17 de noviembre de 2000), al que siguieron otros pronunciamientos en igual sentido, de 13 de julio de 2001 y 28 de noviembre de 2001. Véase Anne-Marie Duguet, "Wrongful life: the recent French Cour de Cassation decisions", in European Journal of Health Law, N 9, Leiden-Boston, 2002, pp. 143-146. 
$\operatorname{lidad}^{36}$, se excluye la posibilidad de reclamar una indemnización por el hecho del nacimiento.

Frente a esto, aunque en Estados Unidos la mayoría de los tribunales superiores de cada uno de los estados se han pronunciado en contra de estas reclamaciones de responsabilidad cuando han tenido ocasión de ello ${ }^{37}$, existen diversos estados en que esta acción de responsabilidad se ha estimado; tal es el caso de California, Colorado, Nueva Jersey y Washington ${ }^{38}$. Ahora bien, hay que destacar que el rechazo en alguno de los estados de este país ha venido de la mano de los propios legisladores estatales ${ }^{39}$, que se han pronunciado expresamente en contra de estas acciones (en general, también en contra de las acciones de wrongful birth), como vía para atajar desde un principio o para limitar las posibles demandas que pudieran plantearse ante sus tribunales en contra del bien vida ${ }^{40}$.

Por último, hay que señalar que en España existe algún pronunciamiento judicial en que se concede una indemnización al niño por estos hechos (v.gr., SSTS 18 de diciembre de 2003 y 18 de mayo de 2006). No obstante, es difícil situar a este país dentro de la excepción a la regla general de rechazo de las acciones de wrongful life, puesto que la estimación del resarcimiento al niño en las sentencias mencionadas no parece ser fruto de una reflexión profunda o de un razonamiento jurídico reposado y consciente de la trascendencia que ello supone ${ }^{41}$. Con todo, estos pronunciamientos

${ }^{36}$ Concretamente, los técnicos de diagnóstico prenatal y los ginecólogos comenzaron una huelga en protesta por estas sentencias, a la vez que las asociaciones de familiares de discapacitados protestaban por el efecto que podían tener tales fallos sobre la concepción social frente a los discapacitados. En paralelo, el Comité consultatif national d'éthique pronunció una recomendación en que se recordaba la solidaridad frente a los discapacitados y la libertad de decisión de la madre. Igualmente, hubo varios tribunales inferiores que se resistieron negaron la aplicación de esta jurisprudencia (v.gr., Cour d'Appel Aix en Provence, 21 de marzo de 2001 y Cour d'Appel Orleans, 22 de octubre de 2001).

${ }^{37}$ Frente a la aceptación en tres estados, estas acciones han sido rechazadas en veintitrés. Véase Michael A. Berenson, "The wrongful life claim - The legal dilemma of existence versus nonexistence: To be or not to be", en Tulane Law Review, No 64, Louisiana, 1990, p. 901 n. 30, para una lista de los eEstados que rechazan esta acción.

${ }^{38}$ Véanse los casos Park vs. Chessin, Curlender vs. Bio-Science Laboratories, Turpin vs. Sortini y Harbeson vs. Parke-Davis Inc.

${ }^{39}$ Concretamente, rechazan ambas acciones Dakota del Sur, Idaho, Indiana, Minnesota, Missouri o Pennsylvania. Por su parte, Dakota del Norte sólo rechaza la acción de wrongful life. En general, el texto sobre el que se apoya el rechazo de estas acciones es parecido al siguiente: "there shall be no cause of action on behalf of any person based on the claim that but for an act or omission, a person would not have been permitted to have been born alive but would have been aborted".

${ }^{40}$ Como excepción en este punto, el estado de Maine ha admitido expresamente las acciones de wrongful birth y de wrongful life, aunque las limitan a ciertos gastos.

${ }^{41}$ Una clara muestra de ello se puede encontrar en la STS de 18 de diciembre de 2003. Véase mi comentario (n. 18), pp. 1.033-1.035. 
del Tribunal Supremo español, junto con el caso estadounidense, muestran que no existe una respuesta unánime respecto de la valoración de estas acciones de responsabilidad civil que permita cerrar la polémica que existe en torno a las mismas.

\section{ANÁLISIS DE LAS ACCIONES DE WRONGFUL BIRTH Y WRONGFUL LIFE DESDE UNA PERSPECTIVA JURÍDICA}

Este panorama que ofrece el Derecho Comparado resulta interesante, en tanto que puede servir de orientación respecto de cuál pueda ser el destino que vayan a tener las acciones de wrongful birth y wrongful life en cualquier ordenamiento en el que éstas se planteen por primera vez. La universalidad de la problemática que suscitan estas demandas de responsabilidad aconseja tener en cuenta cuál ha sido su tratamiento en otros ordenamientos, aunque sólo sea por la mayor experiencia que tienen en tratar este tipo de supuestos.

Ahora bien, este panorama ha de tomarse como una mera orientación o aproximación, pues la estimación o desestimación de estas demandas de responsabilidad civil deberá venir determinada por el estudio concreto de 184 la concurrencia o no, en estos casos, de los elementos de la responsabilidad civil. Éste es el enfoque con el que se ha de abordar el análisis de las acciones de wrongful birth y wrongful life; se ha de comprobar si, en el caso aquí planteado, existe una acción u omisión culpable que causa un daño jurídicamente indemnizable.

Pues bien, cuando se observa la reclamación de los progenitores y del niño desde esta perspectiva, se aprecia que los obstáculos principales a la concesión de una indemnización se centran en dos de los elementos de la responsabilidad civil: el daño y la relación de causalidad. En el estudio de estas acciones normalmente se ha puesto de relieve que en el supuesto de hecho que da lugar a las demandas de wrongful birth y wrongful life resulta difícil identificar un daño, en tanto que éste se encuentra relacionado con el inicio de la vida, o con esta misma; pero junto a este obstáculo, no es tampoco despreciable el que supone la necesidad de enlazar el comportamiento del profesional sanitario que omite una información sobre el estado de salud del embrión o feto, o sobre los riesgos que amenazan a la descendencia futura, con el hecho del nacimiento del niño y las consecuencias derivadas de su situación enferma. El análisis jurídico de esta problemática se ha de centrar en estos dos elementos. 


\section{El problema de identificar un daño en el hecho de la vida}

En la mayoría de los ordenamientos, en los que no se define ni limita el concepto de daño susceptible de ser reparado a través de la acción de responsabilidad civil, el daño aparece identificado como un concepto jurídico indeterminado, cuya definición queda en manos de los tribunales en cada caso concreto. Es por este motivo que, en la actualidad, la pretensión de incremento de las funciones de la responsabilidad civil se manifiesta especialmente a través de la ampliación del concepto de daño; la ausencia de una definición legal de este elemento permite que, a través de sus demandas de responsabilidad civil, los particulares traten de encajar en él determinados perjuicios que padecen y que, hasta el momento, no habían sido aún considerados por los tribunales como susceptibles de recibir una reparación. Tal es el caso del hecho del nacimiento, que, al producirse en unas circunstancias de enfermedad del recién nacido, suscita la cuestión de si puede considerarse en sí mismo como un daño. Frente a esta pretensión, la idea de que la vida es uno de los bienes fundamentales de la persona, cuya protección está garantizada en la mayoría de los ordenamientos, choca contra la calificación de este bien como daño susceptible de indemnización y obstaculiza la reclamación de los actores de las demandas de wrongful birthy wrongful life. Ahora bien, frente a este rechazo en bloque, ha de tenerse en cuenta que la pretensión de indemnización de los progenitores, por un lado, y del propio niño, por otro, presenta distintos perfiles que aconsejan un tratamiento individualizado de este problema.

\section{a) El daño en las demandas de wrongful birth}

A través de las acciones de wrongful birth se reclama responsabilidad a un profesional sanitario cuya conducta ha permitido, en determinadas circunstancias, que se haya producido el nacimiento o la concepción de un niño discapacitado. Este nuevo ser ocasiona a los progenitores gastos, así como problemas y tensiones con las que ellos no contaron a la hora de concebir y que se podrían haber evitado si el niño no hubiera nacido. Este presupuesto básico sobre el que se asientan estas demandas de responsabilidad civil arrastra consigo una gran dificultad a la hora de establecer el daño que sirve de base a la reclamación de los progenitores. Por un lado, se suele señalar -fundamentalmente, entre los autores alemanes- que esta consideración de la vida de una persona como daño para otra rebaja el valor de la primera frente a la segunda y lesiona su dignidad, lesión que se incrementa desde el momento en que se trata de reducir el valor de una persona a los costos que origina ${ }^{42}$.

${ }^{42}$ Aunque sostenida, principalmente por Edward PICKER, Schadensersatz für das unerwünschte eigene Leben. "Wrongful life", Tübingen, Mohr Siebeck, 1995, p. 31, la idea básica 
Por otro lado, la relación que tiene el daño reclamado en la demanda con el hecho de la vida de un nuevo ser suscita dudas respecto de la caracterización del mismo como daño resarcible, sobre todo cuando se alude por parte de diversos autores a los beneficios que conlleva la paternidad y la alegría derivada del nuevo ser, que compensan cualquier posible perjuicio derivado del hecho del nacimiento ${ }^{43}$. Aunque esta supuesta bendición no lleva a negar directamente el hecho del daño por el nacimiento de un hijo enfermo ${ }^{44}$, sí lleva, en ocasiones, a propugnar una rebaja en la indemnización solicitada. Ahora bien, la base de esta argumentación tiene ciertas reminiscencias religiosas, morales o éticas que parten de la idea de que toda vida es siempre una bendición; creencia que se pone en cuestión por la propia reclamación de los progenitores, lo que permite que se desarrolle la polémica sobre el concepto de daño $0^{45}$.

En vista de que esta polémica es difícil de resolver, en las demandas de wrongful birth se han buscado caminos alternativos a través de los cuales lograr la satisfacción del interés de los progenitores de recibir una indemnización, tratando de eludir, al mismo tiempo, que el daño se centre en el hecho del nacimiento de su hijo. Se parte, pues, de la afirmación de que éste no es, en sí mismo, un daño ${ }^{46}$, y se trata de identificarlo con otros intereses o derechos de los progenitores que se han visto lesionados por el comportamiento del profesional sanitario.

Esta técnica, de separar el daño reclamado del hecho de la vida del niño nacido con la enfermedad o defecto, surge entre la jurisprudencia alemana en

de este rechazo la expresa Stephan Ostheide, Die schadensersatzrechtliche Problematik des unerwünschten Kindes im deutschen Zivilrecht, Frankfurt a.M., Peter Lang, 2000, p. 35, cuando indica que el nacimiento y la existencia del niño como tales no pueden ser considerados un evento dañoso, ya que su propia esencia se opone a ello.

${ }^{43} \mathrm{El}$ origen de este argumento se encuentra en el Derecho anglosajón, en torno al reconocimiento de la llamada "regla del beneficio" (offset rule o bennefits rule). A partir de esta idea, se trata de reducir la indemnización reclamada por los progenitores, sobre la consideración de que en su cálculo se han de tener en cuenta otras circunstancias -los beneficios de la paternidad- que influyen en el monto del daño.

${ }^{44}$ Sirvan de ejemplo las palabras del caso Atlanta Obstetrics \& Gynecology Group $v$. Abelson: "we would not even consider the theory that the joy of parenthood should offset the damages. Would anyone in their right mind suggest that where a healthy fetus is injured during delivery the joy of parenthood should offset the damages?".

${ }^{45}$ Señalan al respecto François Terre, Philippe Simler et Yves Lequette, Droit civil. Les obligations, $7^{\mathrm{a}}$ ed., Paris, Dalloz, 1999, p. 638, que afirmar que todo nacimiento es un evento feliz : "c'est faire œuvre de théologie ou de littérature, mais pas nécessairement de droit".

${ }^{46}$ Esta afirmación puede encontrarse, por ejemplo, tanto entre autores españoles (v.gr., Gema Díez-Picazo Giménez, "La imposibilidad de abortar: un supuesto más de responsabilidad civil", en La ley, No 3, D-168, Madrid, 1998, p. 1.706 o MARTín CASALS y SOlé Feliú (n. 7), pp. 1.110-1.111), como alemanes (v.gr., Picker (n. 12), pp. 501-503 u OsTHEIDE (n. 42), pp. 34-35). 
relación con otra de las acciones de responsabilidad civil que tienen que ver con el hecho de la vida: las acciones de wrongful conception (en las que lo que se reclama es una indemnización por el nacimiento de un hijo sano, pero no deseado, puesto que los progenitores habían tratado de evitar, este nacimiento). El argumento que se emplea allí para conceder una indemnización a los progenitores se apoya en la idea de que, desde un punto de vista teórico, es posible distinguir entre la vida o el nacimiento del niño y los gastos que genera su mantenimiento (alimentos). Pese a que este intento de separación no logra eludir por completo las críticas doctrinales ${ }^{47}$, lo cierto es que se trata de una fórmula que facilita de manera considerable el reconocimiento de las demandas de responsabilidad interpuestas por los progenitores en ese otro contexto. Por este motivo, en el caso de las acciones de wrongful birth, los progenitores aplican igualmente esta doctrina de la separación (Trennungslehre) y centran la pretensión de reparación en otros daños o perjuicios que experimentan en relación con el comportamiento del profesional sanitario que no les informó de los defectos o enfermedades que padecía el embrión o feto o de los riesgos que amenazaban a la descendencia futura, aún no concebida.

A partir de esta idea, la pretensión de indemnización se suele centrar, principalmente -según cuál sea el supuesto de hecho-, bien en la privación de la libertad de procreación a ambos progenitores (supuestos de errores en el diagnóstico preconceptivo), bien en la privación a la gestante de la facultad de interrupción voluntaria del embarazo (error en el diagnóstico prenatal $)^{48}$. Aunque la identificación de este daño no queda libre de

${ }^{47}$ La crítica se centra en que la indemnización de los gastos generados por el niño produce una degradación de éste, que pasa a ser considerado un mero objeto y en que la calificación de la carga de alimentos como daño lleva consigo una lesión de la dignidad humana. Tales críticas, defendidas, entre otros por Picker (n. 12), pp. 519, 527-529, 535538 y LANKERS (n. 23), p. 388, son contestadas, sin embargo, por otros muchos autores (v.gr., Ostheide (n. 42), pp. 164-165, o Reinhard Merkel, "Wrongful birth- wrongful life: die menschliche Existenz als Schaden?”, in Ulfrid Neumann und Lorenz Schulz (eds.), Verantwortung in Recht und Moral, Stuttgart, Franz Steiner Verlag, 2000, pp. 180-183).

${ }^{48}$ El daño se identifica con la privación de la facultad, no con la pérdida de la oportunidad de haber podido evitar el nacimiento o la concepción. Se rechaza así la aplicación de la teoría de raíz francesa de la pérdida de oportunidades. Pese a que varios autores la han aplicado aquí de forma consciente o inconsciente (sirva de ejemplo el anglosajón John SEYMOUR, Childbirth and the law, Cornwall, Oxford University Press, 2000, pp. 87 and 93 o los franceses Daniel Malicier, Alain Miras, Pierre Feuglet, et Pierre Faivre, La responsabilité médicale. Données actuelles, $2^{\mathrm{a}}$ ed., Paris, Editions Eska-Editions Lacassagne, 1999, p. 28), considero sumamente acertada la crítica que formula a la misma en estos casos Miquel MARTín CASALS, "Wrongful conception and wrongful birth cases in Spanish law: two wrongs in search of a right", in Ulrich Magnus, Jaap SpIER, Helmut KozIOL, European Tort Law. Liber amicorum for Helmut Koziol, Frankfurt a.M., Peter Lang, 2000, pp. 200-202, que afirma que no existe una verdadera oportunidad perdida respecto del nacimiento y los gastos consiguientes, al residir la decisión del aborto en la madre y no en un evento incierto o aleatorio. 
objeciones, pues lleva consigo la dificultad de la valoración del mismo -dificultad que se puede paliar si se toma como referencia u orientación el gasto unido al nacimiento de un niño en condiciones enfermas, en tanto que las opciones de las que se privó a los progenitores pretendían permitirles la decisión sobre si asumirlos o $\mathrm{no}^{49}-$, lo cierto es que permite eludir, o al menos atenuar, el debate ético sobre el bien vida y su concepto como daño, facilitando la estimación de la demanda.

Lo mismo ocurre con la identificación del daño en el dolor que experimentan los progenitores por el hecho de contemplar al hijo enfermo o por el gasto que les causa la condición enferma; daño indirecto o de rebote distinto del hecho de la vida del niño y por el que, en ocasiones, también se ha concedido la indemnización por wrongful birth ${ }^{50}$. Ahora bien, el debate se ha centrado aquí en qué partidas indemnizatorias incluye este daño; es decir, qué gastos derivados del nacimiento del hijo pueden dar lugar a una indemnización a los progenitores: si los gastos derivados de la condición enferma del niño (gastos especiales por cuidados médicos, educación, etc. $)^{51}$ o todos los gastos derivados del nacimiento ${ }^{52}$. Aunque la cuestión es debatida, la primera opción parece contar con más partidarios ${ }^{53}$.

${ }^{49}$ Tal valoración es propuesta por MARTín CASALS (n. 48), p. 207. Esto no supone alegar que el profesional sanitario cause estos gastos; lo que causa es la privación de la facultad o de la libertad de decisión, cuyo valor se fija en atención a las cargas patrimoniales y morales que se buscaban evitar.

${ }^{50}$ Así, por ejemplo, en el caso de España, se reconoce una indemnización a los progenitores derivada del daño que les supone la situación enferma del niño en las sentencias del Tribunal Supremo de 6 de junio de 1997 y 21 de diciembre de 2005. Igualmente, en el caso de Estados Unidos, se concede indemnización a los progenitores por emotional distress, entre otros, en los casos Berman v. Allan o Blake v. Cruz.

${ }^{51}$ Véase, en este sentido, v.gr., Dan DobBs, The law of torts, St. Paul, West Group, 2000, pp. 794-796; Emaldi Cirión (n. 15), pp. 237-238 u Ostheide (n. 43), pp. 128-130.

${ }^{52}$ Entre los partidarios de esta opción se cuenta, especialmente, PANTALEón Prieto, Fernando, "Procreación artificial y responsabilidad civil", en Universidad del País Vasco, Departamento DE Derecho Privado, La filiación a finales del siglo XX. Problemática planteada por los avances científicos en materia de reproducción humana, Madrid, Editorial Trivium, 1988, pp. 263, 269-270 y el inglés Bernard Dickens, "Wrongful birth and life, wrongful death before birth and wrongful law", in Sheila McLean, Legal issues in human reproduction, Aldershot, Gower, 1989, p. 87.

${ }^{53}$ Aunque el carácter incurable del mal que afecta al nasciturus o amenaza al concepturus parece situar el problema en términos de no nacer o nacer con todos los gastos consiguientes, tal opción, sin embargo, no es realmente la planteada en el caso concreto, pues el hecho del falso negativo permite establecer la distinción teórica entre lo que se asumió y lo que se podría haber asumido. En efecto, los progenitores manifiestan su voluntad de tener un hijo, luego asumen la existencia del descendiente futuro y los gastos que lleva consigo. Ahora bien, el diagnóstico erróneo condiciona su decisión respecto de la situación enferma del niño, impidiéndoles asumir la decisión respecto de los gastos especiales (asumen tener un hijo, pero no su condición enferma, pues no son informados sobre ella ni previamente a la concepción ni una vez ya concebido). En tanto que estos gastos especiales no van unidos 
Sea como sea que se valore este daño, lo relevante en este punto es que tanto este tipo de daños como el anterior, permiten estructurar una demanda de responsabilidad en la que el daño reclamado no se identifica directamente con la vida del niño, lo que facilita la aceptación de la pretensión ejercitada.

\section{b) El daño en las demandas de wrongful life}

Por el contrario, la pretensión de wrongful life no permite esta separación entre el daño y el hecho de la vida del niño, pues, por un lado, parece quedar fuera de dudas que es la propia vida lo que se reclama como daño y, por otro lado, el niño no es titular de otros derechos o intereses propios cuya lesión se pueda imputar al autor del "falso negativo" en el diagnóstico. De hecho, el intento de identificar un daño en las propias malformaciones o en la enfermedad del niño queda condenado al fracaso, por su descoordinación con el resto de los elementos de la responsabilidad civil: es innegable que tales malformaciones existen y que, con toda seguridad, de ellas deriva el perjuicio del niño, pero su existencia no se debe al comportamiento del profesional sanitario que no las detectó o no las puso de relieve frente a los progenitores; falla, pues, aquí la relación de causalidad entre el daño y el comportamiento del profesional sanitario ${ }^{54}$. Asimismo, tampoco se puede identificar el daño del niño en relación con la privación de la facultad de interrupción voluntaria del embarazo ${ }^{55}$, en tanto que dicha facultad se atri-

al hecho de la concepción, sino al hecho de la discapacidad del niño (respecto de la que los padres no pudieron decidir, pues no llegaron a conocer la información relevante sobre el estado de salud del embrión o del feto), se pueden considerar asumidos sólo los primeros, no los segundos.

${ }^{54}$ Como señala David PACE, "The treatment of injury in wrongful life claims", en Columbia Journal of Law \& Social Problems, No 20, New York, 1986, p. 153, "the plaintiff does not allege that the defendant caused the defect from which he suffers; rather, the plaintiff alleges that the defendant caused his birth. Thus, by isolating the injury as the defect, the court holds the defendant liable for an 'injury' that he has not caused". Junto a ello, esta identificación del daño se critica sobre argumentos más discutibles, como la imposibilidad de identificar en estos casos un daño corporal, en tanto que el niño ha nacido ya con el defecto. Véase Adolf Laufs, "Haftung für Nachkommenschaden nach § 823 BGB", en Neue Juristische Woche, Frankfurt, 1965, p. 1.057.

${ }^{55}$ Existen, no obstante, diversos pronunciamientos en los que parece apuntarse que este daño es el que se reclama como consecuencia de una acción de wrongful life. Dice en concreto la Cour de Cassation (17 de noviembre de 2000): "Attendu, cependant, que dès lors que les fautes commises par le médecin et le laboratoire dans l'exécution des contrats (...) avaient empêché celle-ci d'exercer son choix d'interrompre sa grossesse afin d'éviter la naissance d'un enfant atteint d'un handicap, ce dernier peut demander la réparation du préjudice résultant de ce handicap et causé par les fautes retenues". Igualmente, esta teoría también parece haber sido sostenida en el caso Park $v$. Chessin: "the breach of this right may also be said to be tortious the fundamental right of a child to be born as a whole, functional human being". 
buye generalmente a la gestante en atención a sus propios bienes e intereses, no en atención a los del nasciturus, que no es titular de la misma ${ }^{56}$.

Centrada así la polémica, irremediablemente, en la identificación de la vida como daño, existe una opinión mayoritaria que rechaza la posibilidad de obtener por ello una indemnización. Se argumenta, por un lado, que tal identificación es contraria al concepto de daño ${ }^{57}$; que es imposible, por otro, considerar como daño la vida, que es siempre un beneficio ${ }^{58}$; o, también, que, de acuerdo con la teoría de la diferencia, no existe un daño, pues es imposible establecer una comparación entre la existencia enferma (situación actual de la víctima tras el evento dañoso) y la inexistencia (situación en la que se encontraría la víctima de no haber existido tal evento ${ }^{59}$. Ante una argumentación con razonamientos de tanto peso, el estudio de la responsabilidad civil respecto de esta acción finalizaría aquí: no hay daño jurídicamente indemnizable y, por tanto, no existe responsabilidad.

Ahora bien, frente a esta posición mayoritaria, no falta tampoco quien responde a esta argumentación y la critica, por no ser concluyente. De hecho, la cuestión que plantea la reclamación por wrongful life no es tan clara cuando se percibe que parte del problema que subyace al rechazo de la indemnización reside en el propio concepto de daño y en cómo incide sobre él el hecho de que la vida sea un bien jurídicamente protegido en la

${ }^{56}$ Esta afirmación se puede encontrar en varios ordenamientos. Así, pueden citarse, entre otros, autores anglosajones Patrick KeLley, "Wrongful life, wrongful birth, and justice in tort law", Washington University Law Quarterly, No 4, Saint Louis, 1979, pp. 940-941; italianos PAlmerini, Erica, "Note di commento: Il diritto a nascere sani e il rovescio della medaglia: esiste un diritto a non nascere affatto?", in Nuova Giurisprudenza Civile Comentatta, $\mathrm{N}^{\mathrm{o}} 2$, Padova, 2001, pp. 211-212 o alemanes Picker (n. 42), pp. 49-53. Por parte de los tribunales, esta idea está presente, por ejemplo, en España, en la STC 53/1985, de 11 de abril, así como en el caso inglés McKay v. Essex Area Health Authority.

${ }^{57}$ Véase, especialmente, Picker (n. 12), pp. 535-538 y 543-546, que habla de la contrariedad a la moral o al orden público. No se trata, sin embargo, de argumentos concluyentes, puesto que, como pone de relieve TefF (n. 20), pp. 438-439, los argumentos de orden público han sido utilizados por los tribunales estadounidenses en ciertos casos, pero han sido rechazados en otros.

${ }^{58}$ Así se ha afirmado, por ejemplo, en diversos casos de la jurisprudencia estadounidense (v.gr., Berman v. Allan o Gleitman v. Cosgrove). Frente a ello, se critica esta argumentación, entre otros motivos, porque se trata de un razonamiento simbólico o idealista, más que jurídico véase Ricardo de Ángel YáGÜEz, "Diagnósticos genéticos prenatales y responsabilidad, parte II", en Revista de Derecho y Genoma Humano, No 5, Bilbao, 1996, pp. 152-153 o TefF (n. 20), pp. 427-428.

${ }^{59}$ La comparación no es posible puesto que uno de los términos de la misma no es conocido, ni resulta cognoscible. Así lo afirman, PACE (n. 54), pp. 150-151 o WinTer (n. 21), p. 333, así como el caso estadounidense Gleitman v. Cosgrove. Frente a ello, consideran inapropiada y rechazan por ello la aplicación de esta teoría a las acciones de wrongful life, entre otros, TefF (n. 20), pp. 434-435 y Guido TEDeschi, "On tort liability for wrongful life", in Israel Law Review, $\mathrm{N}^{\mathrm{O}}$ 4, Jerusalem, 1966, pp. 537-358. 
mayoría de los ordenamientos. Para comprender este pretendido obstáculo, hay que partir de que el daño se identifica en general con la idea de lesión a un bien o interés protegido o valorado positivamente por el legislador ${ }^{60}$; pero determinar cuáles son estos bienes o intereses es algo que depende de los valores aceptados en la sociedad en cada momento. Para identificar cuáles son, es cierto que puede tener relevancia el enfoque de la moral y de la ética que anteriormente se ha rechazado como criterio único para resolver la problemática que plantean las acciones aquí analizadas, pero sólo la tiene en la medida en que los valores éticos o morales coincidan con valores o principios recogidos en el ordenamiento (por ejemplo, como principios constitucionales o, en general, como principios generales del Derecho). En este sentido, no hay duda de que el bien vida es un bien protegido y valorado no sólo desde la ética o la moral sino, también, desde las normas jurídicas, cuyo resguardo suele encontrarse, además, recogido al más alto nivel, en los textos constitucionales. Este punto de partida parece excluir la calificación de la vida como daño, puesto que supondría considerar como perjuicio lo que el ordenamiento entiende como bien jurídicamente protegido y valorado ${ }^{61}$. Dicho de otra forma: siendo la vida un bien relevante para los ordenamientos, en general, parece que el daño en relación con ella surge por las lesiones que se puedan inferir, y no, como pretende la reclamación de wrongful life, por el hecho de la existencia de este bien jurídico.

Este razonamiento parte de la premisa de que el reconocimiento y protección de la vida por parte de los ordenamientos tiene un carácter absoluto e indiscutible, que excluye por principio poder plantearla como daño. Sin embargo, esto no es completamente cierto; de hecho, si se estudia el tratamiento que recibe el bien vida en la mayoría de los ordenamientos, se observa que su protección o reconocimiento no es nunca absoluto, puesto que siempre se contemplan ciertas excepciones al mismo, algunas de ellas ya asentadas (v.gr., la legítima defensa o el estado de necesidad), otras aún discutidas (v.gr., la eutanasia, la pena de muerte, la propia despenalización de la interrupción voluntaria del embarazo), que demuestran que, jurídicamente, el derecho a la vida no absoluto, sino que puede someterse a límites

${ }^{60}$ Respecto de este concepto “objetivo" de determinación del daño (es daño resarcible el que lesiona determinados bienes), ha de tenerse en cuenta, especialmente, Karl Larenz, Lehrbuch des Schuldrechts. Band I. Allgemeiner Teil, 14 a ed., Múnich, C.H. Beck, 1994, pp. 426-427.

${ }^{61}$ De hecho, algunos autores señalan que la consideración de la vida como daño puede llevar a erosionar el valor de este bien en el ordenamiento, desvalorización que, con el tiempo, puede derivar en la aceptación de atentados contra la vida. Por todos, Picker (n. 12), pp. 544-545. En un sentido similar se pronunciaban los tribunales estadounidenses en el caso Blake $v$. Cruz. 
que, en el fondo, relativizan su pretendido carácter absoluto y excluyente. Más aún, en muchos ordenamientos, los límites a la protección de este bien jurídico se manifiestan en un cierto reconocimiento de la disponibilidad sobre el mismo por parte de sus titulares; disponibilidad que se manifiesta tanto en la licitud de la asunción de actividades arriesgadas que, potencialmente, pongan en peligro el bien vida, como en la no penalización de conductas que tiendan, a ponerle fin por parte de su titular (v.gr., no penalización del suicidio) ${ }^{62}$.

Este punto de partida es ciertamente importante, pues demuestra que la exclusión del concepto de daño del perjuicio en que se apoya la reclamación del niño, parte de una pretendida contradicción que, desde el punto de vista jurídico, no es absoluta: si el carácter del bien vida como jurídicamente protegido, que excluye cualquier atentado contra el mismo, tiene límites, ¿no puede ser uno de estos límites la calificación de la vida como daño bajo ciertas circunstancias, sobre todo, cuando el que realiza dicha calificación es el propio titular? La respuesta a esta pregunta merece, al menos, una reflexión mayor de la que se encuentra detrás del rechazo de la reclamación de responsabilidad civil por wrongful life.

Las dudas, sin embargo, no terminan ahí, puesto que la aparente contradicción entre el concepto de la vida como daño y su protección 192 jurídica como un bien, puede ponerse en cuestión desde otro punto de vista que tiene que ver con el contenido de esta protección y con cómo choca ésta, con la reclamación del niño. Concretamente, las dudas surgen del hecho de que el reconocimiento de la vida y su protección va dirigido en los ordenamientos a excluir ataques contra ella que pretendan poner fin a la misma; no, en cambio, a excluir ataques contra su concepto como bien supremo ${ }^{63}$. A partir de esta idea, se puede afirmar que la reclamación de un daño por el hecho de vivir no es contrario a la protección que contiene el ordenamiento, pues tal protección se dirige a la preservación física o material de la vida, no a mantener un determinado concepto de

${ }^{62}$ Aunque generalmente no se admite un derecho a la muerte, sí existe una cierta disponibilidad sobre la propia vida, que es justificada por algunos sobre la base del derecho a la libertad, v.gr., Aurelia María Romero Coloma, La medicina ante los derechos del paciente, Madrid, Montecorvo, 2002, pp. 162, 174. De hecho, indica Pilar Gómez Pavón, Tratamientos médicos: su responsabilidad penal y civil, Barcelona, Bosch, 1997, pp. 17-18, que la protección de la vida no alcanza a los ataques que provienen de su propio titular y que existe una disponibilidad de este bien para su titular.

${ }^{63}$ En este sentido, Merkel (n. 47), p. 181, por ejemplo, parece cuestionar la imagen de la vida que se pretende proteger con posiciones que se apoyan en su valor supremo, señalando que la protección de este bien es respecto a su imagen en sí misma, no respecto de intereses individuales. Tal imagen, por un lado, puede cambiar y, por otro lado, no se puede oponer a estos intereses individuales. 
la misma como absoluta ${ }^{64}$. Por tanto, la relativización que, en su caso, conlleva la identificación de la vida como daño, se produce en torno a la idea de la vida como bien absoluto, pero no en torno a su protección. La demanda de wrongful life no plantea una verdadera contradicción con los valores supremos del ordenamiento, pues no incide de forma directa sobre el contenido principal de los mismos (la protección de la vida); la pretensión del niño no supone realmente un ataque al bien vida que lo ponga en peligro: ni se trata de acabar con la existencia del niño, ni de negar su derecho a ella.

A partir de estos argumentos, el rechazo absoluto de la reclamación del niño apoyado en el concepto de daño puede ser puesto, al menos, en duda. Realmente no es tan grande el paso que supone aceptar una reclamación de responsabilidad por parte del titular del bien vida en estos casos puntuales de las demandas de wrongful life. La reclamación de una indemnización por el hecho de vivir en este contexto no contradice ni erosiona el valor de la vida, sino que muestra la particular valoración de un sujeto respecto de uno de sus derechos. Junto a ello, el hecho de que la reclamación de responsabilidad civil no pretende destruir o poner fin a la vida del niño, sino sólo obtener una indemnización que compense o resarza al titular del hecho de llevar una vida gravemente enferma -no un ataque, pues, al bien vida, sino a su idea como valor supremo-, permite, como mínimo, dudar del rechazo inicialmente categórico de este daño, pues éste parece estar influido por consideraciones éticas o morales, que, por principio, excluyen a radice toda posibilidad de erosionar el bien vida. Por ende, si se mira más allá de estas ideologías, opiniones y creencias -en la medida de lo posible-, se observará que existe una posibilidad de establecer un daño en relación con la demanda de wrongful life; no se puede descartar, sin más, la concurrencia del elemento del perjuicio en estas acciones. Por eso, aunque la cuestión siga siendo dudosa, merece la pena avanzar en el estudio de la responsabilidad civil en estos casos, para ver si, salvando el obstáculo del daño, existen otros argumentos en contra.

${ }^{64}$ Véase Michael KeLLY, “The rightful position in wrongful life actions”, in Hastings Law Journal, No 42, San Francisco, 1991, p. 536. Cita en concreto el caso Turpin v. Sortini en el que se decía: "it is hard to see how an award of damages to a severely handicapped or suffering child would disavow the value of life or in any way suggest that the child is not entitled to the full measure of legal and nonlegal rights and privileges accorded to all members of society". Igualmente, entre los autores alemanes declara Herbert HARRER, Zivilrechtliche Haftung bei durchkreutzter Familienplannung, Frankfurt a.M., Peter Lang, 1989, p. 35, que la protección constitucional de la vida se despliega en sentido biológico y sicológico, pero que no se ve alterada por el reconocimiento de un derecho a indemnización. 


\section{El verdadero obstáculo a la reclamación de responsabilidad por wrongful birth o wrongful life}
a) La relación de causalidad entre el comportamiento
del profesional sanitario y el daño reclamado
por los progenitores o por el niño

A pesar de que el daño es el elemento de la responsabilidad civil que más ha llamado la atención a la hora de abordar el estudio de este tipo de acciones de wrongful birth y wrongful life, desde un punto de vista jurídico es igual de importante el problema que plantea la identificación de un nexo causal que enlace el daño reclamado por los progenitores o por el propio niño con el comportamiento del profesional sanitario que no informó a los progenitores o a la gestante de los males o enfermedades presentes en el embrión o feto, o de los riesgos que amenazaban a la descendencia futura ${ }^{65}$. La dificultad de establecer este enlace causal se incrementa aquí, por el hecho de que en el curso causal puesto en marcha por el comportamiento del profesional sanitario están presentes determinados comportamientos hipotéticos y determinadas incertidumbres que complican la posibilidad de establecer un enlace preciso y directo entre la acción u omisión del médico y el daño reclamado ${ }^{66}$, hasta el punto de que, en ciertos casos, este nexo 194 causal resulta imposible de afirmar y es, pues, obligado a rechazar la pretensión de indemnización ejercitada por los progenitores o por el niño.

Desde la perspectiva fáctica de la relación de causalidad, el principal problema se encuentra en el enlace causal entre el comportamiento del profesional sanitario y los daños asociados a eventos posteriores al nacimiento del niño (esto es: el daño derivado del hecho de vivir que se reclama en

${ }^{65}$ Véase, en este sentido, Ángel Yágüez (n. 58), p. 145 o Pantaleón Prieto (n. 52), p. 272. Del mismo modo, entre la jurisprudencia, la STS 7 de junio de 2002 rechazó la acción de wrongful birth por la imposibilidad de establecer una relación de causalidad (pues no se puede conocer cuál habría sido la decisión de la gestante sobre el aborto).

${ }^{66}$ De hecho, es frecuente que se niegue la responsabilidad civil en estos casos sobre la idea de que no se puede saber realmente si la madre habría abortado o si los progenitores habrían decidido no procrear. La dificultad de semejante decisión, los numerosos factores que se encuentran implicados (ideológicos, morales, familiares, económicos, etc.) y la distinta relevancia que tengan cada uno de ellos en el ánimo de los titulares de la decisión impide que se pueda afirmar con certeza que se habría adoptado la determinación de abortar o de no concebir. Rodrigo Bercovitz Rodríguez-Cano, "Sentencia del Tribunal Supremo de 7 de junio de 2002", en Cuadernos Civitas de Jurisprudencia Civil, No 59, Navarra, 2002, p. 864). Pese a la gravedad de las lesiones que experimenta el niño, no se puede afirmar con seguridad qué habría decidido la madre, pues ni siquiera ésta podría saber a ciencia cierta qué es lo que habría hecho. Por ello, se afirma que estamos ante un curso causal hipotético o no verificable, véase ÁNGEL YáGüEZ (n. 58), pp. 146 y 149. Sobre estos argumentos y las objeciones al respecto, véase mi monografía (n. 17), pp. 470-477. 
la acción de wrongful life y el daño indirecto que alegan sufrir los padres a través de las demandas de wrongful birth). Dicho de otra forma, la dificultad de afirmar un enlace causal parece menor cuando el daño que se reclama se apoya en un evento anterior al nacimiento del niño, sea el hecho de la privación de la libertad de procreación o de la facultad de interrupción voluntaria del embarazo.

Así, en principio, no parece complicado establecer que el comportamiento negligente del profesional sanitario que tiene como consecuencia la formulación de un falso negativo en el diagnóstico, incide en forma directa sobre la privación a la gestante de la facultad de interrupción voluntaria del embarazo o sobre la libertad de procreación de los progenitores. No obstante, esta sencillez es sólo aparente, ya que tal afirmación requiere establecer un doble enlace causal: un primer enlace que una el comportamiento del profesional sanitario con el falso negativo ${ }^{67}$; y un segundo de relación entre éste y el daño reclamado. Pues bien, en este segundo paso, la afirmación de un vínculo entre el diagnóstico erróneo y la privación de la facultad de interrupción voluntaria del embarazo o de la libertad de procreación, requiere un razonamiento que excede de lo meramente fáctico. Así, para poder hablar en este contexto de que la privación ha sido causada por el diagnóstico erróneo, hay que argumentar que ese error impide que los progenitores cuenten con la información necesaria para poder adoptar una decisión libre y consciente sobre la concepción, en el caso de privación de la libertad de procreación en el contexto de un error en el diagnóstico preconceptivo, o que, en el contexto de un error en el diagnóstico prenatal, impide por completo que la gestante adopte una decisión sobre la interrupción voluntaria de su embarazo (en los sistemas de motivos o indicaciones) ${ }^{68}$ o le impide adoptarla en condiciones

${ }^{67}$ En este sentido, la relación de causalidad requiere la constatación de que el comportamiento del profesional sanitario produce el defecto del diagnóstico. Esto supone otorgar relevancia causal únicamente a aquellos comportamientos activos u omisivos que repercutan en la elaboración de un falso negativo y no a cualquier comportamiento o evento producido en el curso del proceso de diagnóstico. Habrá que plantearse, pues, si el evento que se imputa al profesional demandado fue o no la causa del defecto de la información o la omisión de la misma. Cuando el evento dañoso no tenga tal trascendencia causal, sino que el falso negativo sea debido a un error médico ajeno a la actuación de los sujetos intervinientes, o a un evento del que, de acuerdo con el sistema de responsabilidad aplicable al caso, no se pueda responsabilizar al profesional, habrá que negar la responsabilidad.

${ }^{68}$ En los sistemas de indicaciones o motivos, la interrupción voluntaria del embarazo asociada al motivo embriopático requiere de un diagnóstico que acredite el estado de salud gravemente enfermo del embrión o feto. En este contexto, la existencia de un diagnóstico que refleja un perfecto estado de salud del embrión o feto, o que omite la información sobre tal estado de salud, impide que concurra el supuesto de hecho del cual parte la facultad de interrupción voluntaria del embarazo. Esto es así porque ésta sólo surge en el caso concreto 
de libertad y conciencia (en los sistemas de plazos) ${ }^{69}$. En definitiva, para afirmar el enlace causal hay que argumentar que la privación o el defecto en la información que reciben los progenitores a través del falso negativo, impide la libre autodeterminación de su conducta, lo que provoca el daño que supone tal privación ${ }^{70}$.

Pues bien, esta argumentación se complica aún más cuando el enlace causal se trata de establecer respecto de los daños que aparejan eventos posteriores al nacimiento (la propia vida del niño y el daño indirecto que sufren los progenitores derivado del estado enfermo del hijo o los gastos de la vida enferma). Para afirmar aquí un enlace causal, es necesario llevar más allá el nexo que se ha establecido hasta el hecho de la privación de la libertad de procreación o de facultad de interrupción voluntaria del embarazo (según cuál sea el caso). Es decir, el enlace causal con los daños posteriores al nacimiento exige afirmar que el hecho de la concepción o el hecho del nacimiento deriva necesariamente de la privación que sufren los progenitores o la gestante. Sin embargo, el problema reside en que, desde un punto de vista físico o fáctico, ni la concepción ni el nacimiento son una causa de que los progenitores no contaran con toda la información en el momento de adoptar una decisión respecto de si concebir o respecto de si interrumpir el embarazo en curso.

196 Es más, si se aplica a este caso el razonamiento jurídico, se torna complicado aceptar en el supuesto del error en el diagnóstico preconceptivo, que el desconocimiento de la existencia de riesgos en la futura descendencia haya condicionado necesariamente -y en ese sentido, causado- un ejercicio positivo de la libertad de procreación; esto es: la concepción del niño,

dispuesto por la norma, pues se trata de un supuesto de despenalización de una conducta típica. Por este motivo, la falta de constatación de la presencia en el feto de una enfermedad grave excluye la posibilidad de subsumir el caso concreto en el supuesto de hecho de la norma, impidiendo que se produzca su consecuencia jurídica: la facultad de interrupción del embarazo. Por tanto, la relación de causalidad entre el comportamiento del profesional sanitario y este daño resulta patente.

${ }^{69}$ Tal idea la recoge EMALdi Cirión (n. 15), pp. 178-179, que exige que el consentimiento se preste de forma libre y consciente. Esto impide considerar perfecta la decisión adoptada cuando se realiza sobre una falsa representación de la realidad, pues en tal caso no hay verdadera autodeterminación.

${ }^{70}$ En palabras de Barry Furrow et al., Health law, St. Paul, West Group, 2000, p. 916: "Altough the birth of the child may be a consequence of the loss of this choice, it is entirely derivate of the primary injury -the loss of an ability to make informed procreative decisions". En el mismo sentido se pronuncia la SAP de Madrid, de 5 de mayo de 1998, cuando afirma: "la no realización de las pruebas, perfectamente posibles, según el estado de la técnica médica o, al menos, la no información sobre su posibilidad, resultados y riesgos, determinó que la demandante careciera del conocimiento sobre la real situación del embarazo y del feto y, en consecuencia, le privó de la posibilidad de decidir lo que estimara más conveniente en virtud del derecho que el legislador le confiere en tales casos". 
el posterior embarazo y los daños asociados al nacimiento. De hecho, los factores que concurren en la decisión de un sujeto sobre la concepción futura son muchos y de muy diverso tipo. Uno de ellos, sin duda, es la posible afección de la descendencia futura, pero no es el único ni tampoco el más relevante en la escala de valores de una pareja concreta, sobre todo cuando en esta materia concurren otros factores igualmente importantes para distintos individuos (ideológicos, religiosos, económicos...). Por todo ello, no se puede afirmar con certeza que el falso diagnóstico haya sido el factor relevante en la decisión de los progenitores de concebir. Dado que la información preconceptiva no es presupuesto legal del ejercicio de la libertad de procreación, el sentido positivo o negativo en que se ejercite no siempre puede ser imputado al comportamiento del profesional sanitario, por lo que es difícil enlazar con éste los daños que derivan de eventos posteriores al hecho de la concepción ${ }^{71}$.

Tal afirmación ha de matizarse, en cambio, si el supuesto del que se parte es el de un error en el diagnóstico prenatal, y el sistema de interrupción voluntaria del embarazo es un sistema de motivos o indicaciones ${ }^{72}$. En este caso, la interrupción voluntaria del embarazo sólo es posible si concurre el motivo o indicación previsto por el ordenamiento. En caso contrario, lleva necesariamente al nacimiento, salvo que este proceso biológico se interrumpa por causas naturales. Por tanto, en este contexto podría afirmarse que la privación de la facultad de interrupción voluntaria del embarazo producida por el error en el diagnóstico que deriva del comportamiento del profesional sanitario causa, desde un punto de vista jurídico, el nacimiento del niño, puesto que elimina el posible obstáculo que podía interponer la gestante a tal resultado ${ }^{73}$. Dicho de otra forma, no poder decidir tiene el

${ }^{71}$ Un razonamiento más extenso puede encontrarse en mi monografía (n. 17), pp. 501-504.

${ }^{72} \mathrm{Si}$ se trata de un sistema de plazos, el problema que se plantea para realizar el enlace causal con los daños asociados a eventos posteriores al nacimiento es similar al que se acaba de estudiar respecto del supuesto de diagnóstico preconceptivo: el defecto en la información ciertamente influye sobre la decisión de la gestante respecto de la interrupción voluntaria, pero no siempre determina el ejercicio de esta facultad en sentido negativo (no interrumpir el embarazo), por lo que no se puede afirmar que el comportamiento del profesional sanitario haya producido el nacimiento.

${ }^{73}$ Ésta es una idea que, aunque no con mucha frecuencia, se baraja por algunos autores. En concreto, en el Derecho francés parece estar presente en Jean-Luc AuberT, "Indemnisation d'une existence handicapée qui, selon le choix de la mère, n'aurait pas dû être (à propos de l'arrêt de l'Assemblée plénière du 17 novembre 2000)", in Dalloz, vol. 6, Paris, 2001, p. 491, cuando declara que el comportamiento negligente del profesional, al impedir la decisión de la madre, es el origen de la situación que resulta de la continuación del embarazo hasta su término. Por su parte, Thomas MAnnsDorfer, "Responsabilidad por lesiones prenatales. Fundamento, wrongful life y tendencias (especial atención al derecho 
mismo efecto que decidir en contra de la interrupción del embarazo (con la diferencia de que, en estos casos, el resultado no es asumido por el titular de la decisión): el embarazo sigue a término hasta el nacimiento.

Recapitulando, es posible establecer un enlace causal fáctico entre el comportamiento del profesional sanitario y los daños reclamados por los progenitores en las acciones de wrongful birth asociados a la privación de la facultad de interrupción voluntaria del embarazo o de la libertad de procreación. Con mayores dudas se puede establecer este nexo con respecto de los daños que tienen que ver con eventos posteriores al nacimiento, sea el daño que se reclama en las acciones de wrongful life relativo a la propia existencia del niño, sea el daño indirecto que reclaman los progenitores en las acciones de wrongful birth. Tal enlace causal podría llegar a afirmarse cuando el contexto en el que surgen estas acciones es el de un error en el diagnóstico prenatal; pero resulta muy complicado establecerlo en el supuesto de un error en el diagnóstico preconceptivo. Por ello, habrá de negarse en esos casos la reclamación de responsabilidad por wrongful life, así como la acción de wrongful birth en cuanto a la pretensión de indemnización de estos daños posteriores al nacimiento del niño en el contexto de un diagnóstico preconceptivo.

198 b) La imputación objetiva de los daños al comportamiento del profesional sanitario causante de los mismos

El problema de la relación de causalidad, sin embargo, no termina aquí, puesto que la estimación de la pretensión ejercitada en el resto de los casos en los que sí existe un enlace causal requiere superar un segundo obstáculo: la imputación objetiva del daño al profesional sanitario demandado, perspectiva jurídica de la relación de causalidad que ha de tenerse en cuenta para completar su estudio, pues así se percibe en diversos ordenamientos jurídicos ${ }^{74}$. De hecho, el problema que ofrece un concepto exclusivamente material de la relación de causalidad, como enlace fáctico de acontecimientos, es su excesiva extensión: la relación causa-efecto se puede extender hasta el infinito. Por ello, la imputación de la responsabilidad por los daños

suizo)", en Revista de Derecho y Genoma Humano, No 15, Bilbao, 2001, p. 101, parece aludir también a esta vía de afirmación de la relación de causalidad cuando afirma: "debido a que los padres no pueden decidir libremente, se hace posible el nacimiento del hijo discapacitado". Posteriormente, añade: "el niño ha nacido, finalmente, por el comportamiento contrario al contrato o a un deber de cuidado del personal médico" (p. 102).

${ }^{74}$ Una perspectiva de Derecho Comparado respecto del binomio relación de causalidad/ imputación objetiva en la responsabilidad civil se puede encontrar en VON BAR (n. 32), p. 438, 440 o Jaap SPIER et al., Unification of Tort Law: Causation, La Haya, Kluwer Law International, 2000, p. 127, en las conclusiones al estudio de derecho comparado del European Group on Tort Law (citando la excepción de Bélgica). 
derivados de una conducta requiere de algo más que la constatación fáctica de un nexo causal; un criterio que discrimine qué daños producidos dentro de un curso causal han ser puestos a cargo del agente ${ }^{75}$.

Esto abre la puerta al estudio de los criterios de imputación objetiva, que adquieren especial importancia para las acciones de responsabilidad civil aquí estudiadas, puesto que, en algunos casos, resultan, incluso, concluyentes. Dicho de otra forma, es la aplicación de los criterios de imputación objetiva la que permite excluir de manera indubitada la reclamación de responsabilidad civil en alguno de los diversos supuestos englobados dentro de las acciones de wrongful birth y wrongful life.

Tal es el caso, por un lado, de la reclamación de wrongful life en su conjunto. Habiendo llegado a la conclusión de que en este tipo de demandas de responsabilidad civil el daño reclamado se centra en el hecho de la vida del niño -se imputa al profesional sanitario responsabilidad porque su comportamiento no permitió evitar el nacimiento o la concepción-, la imputación objetiva del daño reclamado queda excluida de acuerdo con el criterio del fin de protección de la norma, que establece que no pueden ser objetivamente imputados a un sujeto aquellos daños que caigan fuera del ámbito o finalidad de protección de la norma sobre la que pretenda fundarse la responsabilidad del demandado ${ }^{76}$. Por tanto, si el resultado del comportamiento del agente causante no es uno de los que se pretendían evitar con el establecimiento del deber que emana de la norma de cuidado, el autor estará exento de responsabilidad. Dicho de otra forma, sólo serán imputables al agente productor del daño los perjuicios que recaigan sobre aquellos bienes o intereses que la norma buscaba proteger ${ }^{77}$.

${ }^{75}$ Esta función de delimitación de los daños que pueden ser puestos a cargo del causante de los mismos es puesta de relieve por diversos autores en diversos ordenamientos. Entre ellos, destaca Fernando Pantaleón Prieto, "Causalidad e imputación objetiva: criterios de imputación”, en Asociación de Profesores de Derecho Civil, Centenario del Código Civil, Madrid, Centro de Estudios Ramón-Areces, 1990, vol. II.

${ }^{76}$ Así define este criterio Pantaleón Prieto (n. 75), pp. 1.580-1.584; pero la misma idea puede encontrarse en LARENZ (n. 60), p. 440. Según el autor español, se trata de la imputación dentro de la esfera de riesgos típicos de la fuente de peligro que la norma pone a cargo del responsable. Cuando se constata que una determinada conducta infringe una norma, esta constatación sirve para comprobar si la conducta llevada a cabo era una de las que la norma infringida buscaba evitar, en cuyo caso deberá afirmarse la imputación objetiva. De no ser así, se imputaría al particular un evento dañoso que es realización de un riesgo que el legislador aceptaba.

${ }^{77}$ Hay que tener en cuenta que este criterio ha sido criticado en ocasiones por la arbitrariedad que conlleva en la estimación de los intereses a cuya protección se dirige la norma en cuestión. Véase Geneviève Viney y Patrice Jourdain, Traité de droit civil. Les conditions de la responsabilité, $2^{\mathrm{a}}$ ed., Paris, LGDJ, 1998, p. 158. No obstante, según indican Spier y HaAzen n. 74, pp. 139-142, en las conclusiones del European Group on Tort Law sobre la relación de causalidad, el criterio del fin de protección de la norma es una constante presente en la mayoría de los ordenamientos. 
Pues bien, si se observa la pretensión ejercitada en nombre del niño en las acciones de wrongful life, se comprueba que su reclamación se centra en que el profesional sanitario no permitió a los progenitores evitar la concepción o interrumpir el embarazo; con ello, el niño pretende que se han lesionado sus intereses. Sin embargo, ya se ha apuntado que, en la mayoría de los ordenamientos, ni la facultad de interrupción voluntaria del embarazo ni la libertad de procreación se establecen en atención al interés del niño de no nacer, sino en atención a los intereses de la gestante o de los progenitores, que son los que priman y resultan efectivamente protegidos en la situación de conflicto ${ }^{78}$. Ello supone que el fin de protección de la norma que lesiona la conducta negligente del profesional sanitario no busca prevenir los daños que le supone al niño nacer, ni busca garantizar que no nazcan niños enfermos o malformados. Por el contrario, se trata de normas que se establecen en atención de los intereses de los futuros progenitores. Por ello, el daño que le supone al niño el hecho de haber nacido no es concreción del riesgo que se buscaba evitar a través del establecimiento de la norma que regía la conducta del profesional sanitario o la norma de cuidado que ha sido infringida por su comportamiento, motivo por el que ha de afirmarse que este daño no es objetivamente imputable al profesional sanitario cuyo comportamiento impide a los progenitores 200 ejercitar la facultad de interrupción voluntaria del embarazo o la libertad de procreación, pues el fin de protección de la norma no se centra en el interés del niño, sino en el interés de los progenitores, que son los que pueden reclamar un daño por la privación de su libertad de procreación o de la facultad de abortar.

Ahí es, en consecuencia, donde se encuentra el verdadero problema de estas acciones de responsabilidad civil desde el punto de vista de la concurrencia de los presupuestos de esta institución. Pueda o no identificarse un daño en estos hechos y enlazarse tal daño con el comportamiento del profesional sanitario - al menos en el contexto de un error en el diagnóstico prenatal-, subsiste el obstáculo insalvable que ofrece la faceta jurídica de la relación de causalidad. Así, al margen de toda concepción ética o moral de la vida, es un argumento jurídico el que lleva a afirmar de forma concluyente el rechazo de la reclamación de responsabilidad por wrongful life.

Ahora bien, el argumento de la imputación objetiva como límite a las reclamaciones de responsabilidad en el contexto aquí planteado también incide sobre las demandas interpuestas por los progenitores por wrongful birth. Es dudoso que se puedan imputar de manera objetiva al profesional sanitario los daños indirectos o de rebote derivados del hecho del nacimiento del niño. Aunque se pueda establecer respecto de ellos un enlace

${ }^{78}$ Véase supra (n. 56). 
causal con el comportamiento del médico (al menos en el contexto de un error en el diagnóstico prenatal), el criterio del incremento del riesgo pone en duda que se puedan imputar objetivamente estos daños al profesional sanitario. De hecho, conforme a este criterio, no puede atribuirse un determinado daño al comportamiento de un sujeto cuando la conducta del agente no ha sobrepasado los límites del riesgo que es considerado tolerable por el ordenamiento. Así, se niega la imputación objetiva del daño al agente cuando se comprueba que la conducta desarrollada por él, comparada con su alternativa diligente, no incrementa el riesgo de que se produzca el daño en cuestión (es decir, que con seguridad o probabilidad no despreciable, el resultado dañoso se habría producido igualmente, pese al actuar cuidadoso del agente $)^{79}$.

Aplicado al ámbito que aquí nos ocupa, nos encontramos con que la variedad de factores que inciden en la decisión de interrumpir el embarazo por parte del titular de esta facultad impide realizar a priori una afirmación general conforme a la cual se pueda considerar que el comportamiento del profesional sanitario incrementó el riesgo del daño derivado de un evento posterior al nacimiento (esto es: el daño indirecto derivado de la condición enferma del niño). De hecho, no se sabe, ni se puede saber si tal daño se habría producido aun si este sujeto hubiera actuado de manera diligente ${ }^{80}$, pues no se sabe si, de haber recibido la gestante un diagnóstico correcto -es decir, un diagnóstico que reflejara el estado enfermo del embrión o feto-, habría ejercitado la facultad de interrupción del embarazo en sentido positivo (impidiendo el nacimiento y los daños derivados del mismo) o en

${ }^{79}$ Así enuncia esta teoría Pantaleón Prieto (n. 75), pp. 1.577 y 1.590 , que parte del hecho de que no toda conducta que crea un riesgo de lesión de bienes jurídicos protegidos puede ser considerada negligente. Socialmente, se acepta la práctica de determinadas actividades más o menos peligrosas, ya que son útiles para la sociedad o ya que el costo social de las medidas de reducción del riesgo sería grande. Por ello, concluye el autor, que si un riesgo es aceptado en general, no se ve por qué ha de responder aquél que lo realiza por los daños que son consecuencia del mismo.

${ }^{80}$ Lo que es cierto es que, con un comportamiento diligente, el riesgo de un "falso negativo" en el diagnóstico disminuye y que, con ello, aumenta la posibilidad de que los progenitores conozcan el mal o defecto del niño. Ahora bien, el hecho de que aumente esta posibilidad de conocimiento por los progenitores del defecto o enfermedad del niño no determina, que aumente por igual la posibilidad de que no se produzcan los daños unidos al nacimiento. Afirmar lo contrario supondría aceptar que, en este contexto, es más probable optar por interrumpir el embarazo que la opción contraria. Sin embargo, es un hecho que no todos los progenitores que conocen de los defectos de su descendencia optan por el aborto. Por ello, en realidad, no se puede saber de forma general si el comportamiento negligente incrementa el riesgo de los daños posteriores al nacimiento, pues este riesgo deriva de un conjunto de factores subjetivos y personales, que no se pueden conocer ni graduar a priori, ya que dependen de cada persona en cada caso concreto. Véase mi monografía (n. 17), pp. 559-562. 
sentido negativo (permitiendo el nacimiento y las consecuencias unidas a éste). Por tanto, salvo que en el caso concreto se acredite que se produjo de forma efectiva este incremento del riesgo -es decir, que con seguridad o probabilidad no despreciable el resultado dañoso no se habría producido de haber obrado en forma diligente el profesional sanitario, pues la gestante habría optado por la interrupción voluntaria del embarazo ${ }^{81}-$, la conclusión es que no se le pueden imputar objetivamente estos daños al profesional sanitario.

Esto excluye de manera definitiva la reclamación de daños derivados de eventos posteriores al nacimiento del niño en el contexto de las acciones de wrongful birth. Nada obsta, sin embargo, a la reclamación de responsabilidad de los progenitores o de la gestante por el daño que supone, respectivamente, la privación de la libertad de procreación o de la facultad de aborto, sea en el contexto de un error en el diagnóstico preconceptivo o en el diagnóstico prenatal; es a éste, pues, el contexto al que se debería circunscribir la responsabilidad por wrongful birth.

\section{RECAPITULACIÓN}

202 En definitiva, el resultado final que se deriva del estudio desarrollado sobre los elementos de la responsabilidad civil confirma la solución barajada con mayor frecuencia en torno a esta problemática: rechazo de las acciones de responsabilidad por wrongful life y aceptación de las de wrongful birth. Sin embargo, esta solución aparece aquí matizada, por un lado, porque el rechazo de las primeras no se centra en el elemento del daño, como tradicionalmente se ha venido haciendo, sino en el de la relación de causalidad (o, más concretamente, en la imputación objetiva del daño reclamado); y, por otro, porque la aceptación de las segundas se debe limitar (salvo excepciones puntuales) a los daños que derivan de eventos anteriores al nacimiento; esto es, a la privación de la libertad de procreación o de la facultad de interrupción voluntaria del embarazo, según se trate de un supuesto de error en el diagnóstico preconceptivo o de error en el diagnóstico prenatal.

Fuera de estos supuestos, hay que afirmar que no compete a la responsabilidad civil solucionar la situación en que se encuentran los progenitores

${ }^{81}$ Esto deja abierta la posibilidad de que, en un caso concreto, se logre acreditar (v.gr., a través de hechos, declaraciones o indicios) que los progenitores que plantean la demanda por wrongful birth habrían optado por interrumpir el embarazo de haber conocido la información relevante (pues su decisión se habría basado en tal información). Si se logra esa prueba, se podrá afirmar que la conducta negligente del profesional sanitario incrementó el riesgo de la producción de los daños posteriores al nacimiento, ya que en el caso concreto la indeterminación inicial habría quedado concretada en tal sentido. 
y el niño, pero no porque se parta de una determinada idea de la vida que excluya su reclamación como daño, sino porque no se cumplen los presupuestos de la responsabilidad. En tales circunstancias, no hay, pues, más remedio que negar una indemnización por daños. De lo contrario, se entraría en esa dinámica actual de empleo de la responsabilidad para solucionar cualquier contrariedad que sufra una persona; dinámica que no responde a la finalidad y la esencia de esta institución y que debería abandonarse, a no ser que se acompañase de una reforma legal.

\section{BiBLIOGRAFÍA}

Alonso Pérez, Mariano, "La relación médico-enfermo, presupuesto de responsabilidad civil (en torno a la lex artis)", en Juan Antonio Moreno MarTínez (coord.), Perfiles de la responsabilidad civil en el nuevo milenio, Madrid, Dykinson, 2000.

Alloiteau, Sthéphane, "L'arrêt C.H.R. de Nice: l'indemnisation du préjudice lié a un défaut d'information médicale (Conseil d'Etat, 14 février 1997)", in Les Petites Affiches, N $^{\circ}$ 64, Paris, 1997.

Ángel YáGÜEZ, Ricardo de, "Diagnósticos genéticos prenatales y responsabilidad, parte II", en Revista de Derecho y Genoma Humano, No 5, Bilbao, 1996.

Ataz López, Joaquín, Los médicos y la responsabilidad civil, Madrid, Montecorvo, 1985.

Aubert, Jean-Luc, "Indemnisation d'une existence handicapée qui, selon le choix de la mère, n'aurait pas dû être (à propos de l'arrêt de l'Assemblée plénière du 17 novembre 2000)", in Dalloz, vol. 6, No 1, Paris, 2001.

Baudouin, Jean-Louis y Catherine Labrusse-Riou, Produire l'homme: de quel droit? Étude juridique et éthique des procréations artificielles, Paris, PUF, 1987.

Bercovitz Rodríguez-Cano, Rodrigo, "Sentencia del Tribunal Supremo de 7 de junio de 2002", en Cuadernos Civitas de Jurisprudencia Civil, No 59, Navarra, 2002.

Berenson, Michael A., "The wrongful life claim - The legal dilemma of existence versus nonexistence: To be or not to be", en Tulane Law Review, Nº 64, Louisiana, 1990.

Bustos Pueche, José Enrique, "Un caso de voluntarismo judicial: la sentencia del Tribunal Supremo de 6 de junio de 1997", en La Ley, N 5, D-250, Madrid, 1997.

CAPron, Alexander Morgan, "Tort liability in genetic counseling", in Columbia Law Review, N 79, New York, 1979.

Conte, Mario, "Dovere d'informazione e danno biologico: uno strano connubio", in Diritto di Famiglia e delle Persone, anno, xxiv, vol. 2, N 1, Milano, 1995.

DAssio, Michele, "Il principio di irrisarcibilità della nascita indesiderata nell'ordinamento francese", en Antonio D'ANGELO (dir.), Un bambino non voluto è un danno risarcibile?, Milán, Giuffrè Editore, 1999. 
Deguergue, Maryse, "Les préjudices liés à la naissance", in Responsabilité civile et assurances, $\mathrm{N}^{\mathrm{O}}$ spéciale, Paris, 1998.

Dickens, Bernard, "Wrongful birth and life, wrongful death before birth and wrongful law", en Sheila MCLEAN, Legal issues in human reproduction, Aldershot, Gower, 1989.

Díez-PicAzo, Luis, "La responsabilidad civil hoy", en Anuario de Derecho civil, vol. 32, $\mathrm{N}^{\mathrm{O}}$ 4, Madrid, 1979.

Díez-Picazo Giménez, Gema, "La imposibilidad de abortar: un supuesto más de responsabilidad civil", en La ley, No 3, D-168, Madrid, 1998.

Doвbs, Dan, The law of torts, St. Paul, West Group, 2000.

Duguet, Anne-Marie, "Wrongful life: the recent French Cour de Cassation decisions", in European Journal of Health Law, No 9, Leiden-Boston, 2002.

Emaldi Cirión, Aitziber, El consejo genético y sus implicaciones jurídicas, BilbaoGranada, Publicaciones de la Cátedra de Derecho y Genoma Humano y Editorial Comares, 2001.

Finel, Laure, "La responsabilité du médecin en matière de diagnostic des anomalies foetales", in Revue Trimestrielle de Droit Sanitaire et Social, vol. 33, No 2, Paris, avril-juin 1997.

Furrow, Barry et al., Health law, St. Paul, West Group, 2000.

Gallagher, Kathleen, "Wrongful life: should the action be allowed?", in Louisiana 204 Law Review, No 47, Louisiana, 1987.

García Blázquez, Manuel y Juan José Molinos Cobo, Manual práctico de responsabilidad y defensa de la profesión médica (Aspectos jurídicos y médico-forenses), Granada, Comares, 1995.

Gautier, Pierre-Yves, "Les distances du juge. À propos d'un débat éthique sur la responsabilité civile", in La Semane Juridique. Edition Génerale, No 2, I 287, Paris, 10 Janvier 2001.

Gómez Pavón, Pilar, Tratamientos médicos: su responsabilidad penal y civil, Barcelona, Bosch, 1997.

HARRER, Herbert, Zivilrechtliche Haftung bei durchkreutzter Familienplannung, Frankfurt a.M., Peter Lang, 1989.

JACKSOn, Anthony, "Action for wrongful life, wrongful pregnancy, and wrongful birth in the United States and England", in Loyola of Los Angeles International and Comparative Law Journal, $\mathrm{N}^{\circ}$ 17, Los Angeles, 1995.

KeLley, Patrick, "Wrongful life, wrongful birth, and justice in tort law", Washington University Law Quarterly, N 4, Saint Louis, 1979.

KELly, Michael, "The rightful position in wrongful life actions", in Hastings Law Journal, N N $^{\circ}$, San Francisco, 1991.

LANKERS, Winifred, "Zur Abwälzung von Unterhaltskosten", in Zeitschrift für das gesamte Familienrecht, No 7/8, Regensburg 1969.

Larenz, Karl, Lehrbuch des Schuldrechts. Band I. Allgemeiner Teil, $14^{\mathrm{a}}$ ed., Múnich, C.H. Beck, 1994. 
LAufs, Adolf, "Haftung für Nachkommenschaden nach § 823 BGB", en Neue Juristische Woche, Frankfurt, 1965.

Lysaught, Therese, "Wrongful life? The strange case of Nicholas Perruche", in Commonweal, No 129, New York, 2002.

Macía Morillo, Andrea, "Sentencia del Tribunal Supremo de 18 de diciembre de 2003, en Cuadernos Civitas de Jurisprudencia Civil, No 66, Navarra, 2004.

Macía Morillo, Andrea, La responsabilidad por los diagnósticos preconceptivos y prenatales. Las llamadas acciones de wrongful birth y wrongful life, Valencia, Tirant lo Blanch, 2005.

Macía Morillo, Andrea, "Responsabilidad perinatal", de la Enciclopedia de Bioderecho y Bioética, 2008 (en prensa).

Malicier, Daniel, Alain Miras, Pierre Feuglet, et Pierre Faivre, La responsabilité médicale. Données actuelles, $2^{\mathrm{a}}$ ed., Paris, Editions Eska-Editions Lacassagne, 1999.

Mannsdorfer, Thomas, "Responsabilidad por lesiones prenatales. Fundamento, wrongful life y tendencias (especial atención al derecho suizo)", en Revista de Derecho y Genoma Humano, No 15, Bilbao, 2001.

Martín CASAls, Miquel, "Wrongful conception and wrongful birth cases in Spanish law: two wrongs in search of a right", in Ulrich Magnus, Jaap SPIER, Helmut KozIOL, European Tort Law. Liber amicorum for Helmut Koziol, Frankfurt a.M., Peter Lang, 2000.

Martín Casals, Miquel y Josep Solé Feliú, "Sentencia del Tribunal Supremo de 7 de junio de 2002", en Cuadernos Civitas de Jurisprudencia Civil, N $^{\circ} 60$, Navarra, 2002.

Merkel, Reinhard, "Wrongful birth-wrongful life: die menschliche Existenz als Schaden?", in Ulfrid Neumann und Lorenz Schulz (eds.), Verantwortung in Recht und Moral, Stuttgart, Franz Steiner Verlag, 2000.

Ostheide, Stephan, Die schadensersatzrechtliche Problematik des unerwünschten Kindes im deutschen Zivilrecht, Frankfurt a.M., Peter Lang, 2000.

PACE, David, "The treatment of injury in wrongful life claims", en Columbia Journal of Law \& Social Problems, No 20, New York, 1986.

Palmerini, Erica, "Note di commento: Il diritto a nascere sani e il rovescio della medaglia: esiste un diritto a non nascere affatto?", in Nuova Giurisprudenza Civile Comentatta, No 2, ciudad, 2001.

PICKER, Edward, "Schadensersatz für das unerwünschte Kind (Wrongful birth). Medizinischer Fortschritt als zivilisatorischer Rückschritt?", in Archiv für die civilistische Praxis, No 195, Tuebingen, 1995.

PICKER, Edward, Schadensersatz für das unerwünschte eigene Leben. "Wrongful life", Tübingen, Mohr Siebeck, 1995.

Ploscowe, Morris, "An action for wrongful life", in New York University Law Review, No 38, New York, 1963. 
Romero Coloma, Aurelia María, La medicina ante los derechos del paciente, Madrid, Montecorvo, 2002.

Seymour, John, Childbirth and the law, Cornwall, Oxford University Press, 2000.

SHAPIRA, Amos, "Wrongful life lawsuits for faulty genetic counselling: should the impaired newborn be entitled to sue?", in Journal of Medical Ethics, $\mathrm{N}^{\circ}$ 24, London, 1998.

SpIER, Jaap et al., Unification of Tort Law: Causation, La Haya, Kluwer Law International, 2000.

Tedeschi, Guido, "On tort liability for wrongful life", in Israel Law Review, $\mathrm{N}^{\circ} 4$, Jerusalem, 1966.

TefF, Harvey, "The action for wrongful life in England and the United States", in International and Comparative Law Quarterly, vol. 34, Cambridge, 1985.

Terre, François, Philippe Simler et Yves Lequette, Droit civil. Les obligations, $7^{\text {a }}$ ed., Paris, Dalloz, 1999.

Pantaleón Prieto, Fernando, "Procreación artificial y responsabilidad civil", en Universidad del País Vasco, Departamento de Derecho Privado, La filiación a finales del siglo XX. Problemática planteada por los avances científicos en materia de reproducción humana, Madrid, Editorial Trivium, 1988.

Pantaleón Prieto, Fernando, "Causalidad e imputación objetiva: criterios de imputación”, en Asociación de Profesores de Derecho Civil, Centenario del Código Civil, Madrid, Centro de Estudios Ramón-Areces, 1990, vol. II.

Viney, Geneviève y Patrice Jourdain, Traité de droit civil. Les conditions de la responsabilité, $2^{\mathrm{a}}$ ed., Paris, LGDJ, 1998.

Von BAR, Christian, The common european law of torts, Múnich, C.H.Beck, 1998, vol. I.

Weber, Dieter, Arzthaftpflicht für Nachkommenschaftschäden?, Berlín-Heidelberg, Springer Verlag, 1988.

Winter, Thomas, "Leben als Schaden? Vom Ende eines französischen Sonderwegs", in Juristen Zeitung, No 7, Tübingen, 2002.

YzQuierdo Tolsada, Mariano, "La responsabilidad civil ante el nuevo milenio: algunas preguntas para el debate", en Ricardo de ÁNGEL YáGÜEZ y Mariano YZQUIERDo Tolsada (coords.), Estudios de responsabilidad civil en homenaje al Prof. Roberto López Cabana, Madrid, Dykinson, 2001. 